\title{
Heterogeneous labour demand in the Colombian manufacturing sector
}

\author{
Luis E. Arango ${ }^{1 *}$, Francesca Castellani ${ }^{2}$ and Nataly Obando 3
}

\begin{abstract}
Using the Colombian Annual Manufacturing Survey between 2000 and 2013, we investigate the heterogeneity in labour demand within the industrial sector based on the elasticities. We find that long-run own-price, output, and TFP elasticities vary across a variety of dimensions such as regions, sectors, and plant sizes depending on workers' skills and contract modalities (open-ended and temporary). The determinants of industrial labour demand are quantitatively different, mainly, across regions and, to some extent, subsectors when we focus on demand for unskilled workers. It is possible that, given the importance of apparel in the manufacturing sector in Pereira, labour demand for permanent skilled workers in that city is different from that of Bogotá, Cali, and Medellín. Thus, labour demand heterogeneity is just a symptom of the underlying differences in the production processes and produced goods, technologies, labour force qualification and productivity, preferences of workers, rigidities and wage-setting procedures, and peculiarities of goods' markets, etc. Suggestions to induce more wage flexibility and decrease labour segmentation emerge from this paper.
\end{abstract}

Keywords: Regional disparities, Skilled and unskilled workers, Temporary and open-ended contracts, Labour segmentation

JEL Classification: J23, R32

\section{Introduction}

The Colombian labour market is fraught with regional differences. While these disparities might not be particular to Colombia, their intensity and persistence over time is quite significant (Arango et al. 2013). Labour market outcomes such as participation, occupation, and unemployment rates show geographic disparities well above $10 \%$ points across cities. National unemployment rates ${ }^{1}(11.9 \%)$ are unevenly registered, ranging from $7.6 \%$ (in Bucaramanga) to $16 \%$ (in Quibdó). Participation rates go from 59\% (Quibdó) to 71.4\% (Bogotá) and occupation rates from $49 \%$ (Quibdó) to 64\% (Bogotá). Recent research (Arango et al. 2013; Cárdenas et al. 2015), points to the functioning of local labour markets to explain these differences. ${ }^{2}$

For policymakers, private sector firms, workers (trade unions) and job-seekers, understanding such heterogeneity and its features is crucial. On the one hand, a

*Correspondence: larangth@banrep.gov.co

1 Banco de la República, Bogotá, Colombia

Full list of author information is available at the end of the article clear grasp of these disparities is likely to affect employment location, local labour market performance, and skills development strategies (Granato et al. 2015). In the case at hand, the differences in own-price elasticitiesdepending on the skills of workers as well the type of contract modalities (open-ended or temporary)-might prompt the design of policies aimed at reducing real wage rigidities to avoid disproportionate reactions in labour demand when the economy faces a shock. Regional differences in output elasticities might require the design of versatile retraining programs of displaced or required labour force.

On the other hand, labour market policies might engender diverse outcomes, even unintended ones, if such disparities are not correctly factored in. For example, given the geographical differences in local labour

\footnotetext{
1 These numbers are based on January 2016 data from the Colombian Statistical Office (DANE).

2 Regional disparities in labour market outcomes have been extensively studied (see, among many others, Thirlwall 1996; Blanchard and Katz 1992; Elhorst 2003; and more recently, Bande et al. 2008 and Granato et al. 2015).
} 
productivity, the implementation of a single real minimum wage for the whole country might bring about regional divergences in labour informality and unemployment. In addition, public sector wage setting might have some spillover effects upon industrial wages that vary by region. Thus, more coherent wage policies might be necessary. Caponi (2017), by calibrating a search model to Italy, shows that a unique wage policy can generate different effects on employment across regions. In general, if based on aggregate instead of particular elasticities-to account for regional, sectoral, or size differences-policy design might be seriously flawed (Young 2013).

Exploring these disparities requires insights on dimensions such as local productive structures, firm size, and location. In the case of Colombia, investigating labour demand at the industry level, given its employment potential, is a natural starting point. Its heterogeneity is a symptom of the underlying differences in the production processes and produced goods, technologies, labour force qualification and productivity, preferences of workers, rigidities and wage-setting procedures, and peculiarities of goods markets, etc. While several efforts have been made to estimate the labour demand in the manufacturing sector at the national level, few propose a regional focus, as well as attention to sectors ${ }^{3}$ and firm size.

Existing research on the determinants of labour demand in Colombia does not reach unanimous conclusions. Roberts and Skoufias (1997), using the Annual Manufacturing Survey (AMS) data between 1981 and 1987, find that unskilled workers have a higher long-run wage elasticity $(-0.65)$ than skilled ones $(-0.42)$. That is, the former are likely to be more affected by increasing labour costs. Output elasticity is higher for skilled labour (0.89) than for unskilled (0.76), suggesting that output and skilled labour demand move almost proportionally. Regional dummies were included among the control variables.

Using data from the AMS and household surveys between 1980 and 1996, Vivas and Farne (1998) obtain long-run real wage and output elasticities of -0.71 and 1.10, respectively. Exploring the effects of trade liberalization on manufacturing labour demand between 1997 and 1999, Arango and Rojas (2004) estimate elasticities of -0.78 and 0.76 for real wages and output, respectively. With a more recent subsample, the estimates they obtain are -0.92 and 0.67. For Bernal and Cárdenas (2003), based on the information of 2570 AMS establishments between 1978 and 1991, the long-run real wage elasticity is -2.27 and the output elasticity is 0.24 . With a panel

\footnotetext{
${ }^{3}$ Arango and Rojas (2004) made an important contribution with respect to sector levels and firms' age.
}

of 91 manufacturing sectors, they obtain a short-run real wage elasticity of -0.6 and a long run one of -1.43 . Eslava et al. (2010), focusing on joint factor demand and the incidence of adjustment costs, find that the latter are significant and that substitutability-rather than complementarity-among factors emerges during the adjustment process. Medina et al. (2013) study labour demand for the period 1993-2009 and conclude that industrial employment is highly persistent. Production shocks generate a larger response by skilled and unskilled employment than shocks on capital and wages. Less-skilled workers face higher adjustment costs.

Resting on all this literature and the findings of Arango et al. (2013) on the heterogeneity of the labour market outcomes in Colombia, this paper explores industrial labour demand, taking into account the potential regional, subsector, and size disparities, in the line of Adam and Moutos (2014) and Judzik 2015. ${ }^{4}$ To this end, we use the information from the AMS between 2000 and 2013.

Eluding the estimation of aggregate labour demand elasticities to own-price, output, and total factor productivity (TFP), as in previous literature, the paper innovates by discriminating across labour skills of workers and contract modalities. By doing so, a clearer picture emerges as to the implications of shocks faced by firms that employ skilled and unskilled workers, either permanent or temporary. In the case of conditional labour demand, the long-run own-price elasticity fluctuates between -0.256 , for skilled temporary, and -1.109 , for unskilled permanent workers. We also find that the output elasticity oscillates between 0.71 (skilled temporary) and 1.122 (skilled); the long-run TFP elasticities have similar numbers but with the opposite sign. In the case of unconditional labour demand, elasticities are smaller. The results suggest the existence of a two-tier employment regime which point to a partial segmentation of the labour market (see Castellani et al. 2017).

Our results also confirm that disparities do exist in the sense that labour markets are heterogeneous and exhibit segmentation at different dissections. In general, we find that the determinants of industrial labour demand are quantitatively different, mainly across regions and, to some extent, across subsectors and plant sizes, in the

\footnotetext{
${ }^{4}$ Another strand of literature on labour market disparities goes along the lines of Dumais et al. (2002) who show that geographic concentration in U.S. manufacturing industries has been declining over time. Dao et al. (2014) observe lower migration rate across U.S. states during the past 40 years due to higher labour market flexibility. In Europe, the participation rate response to labour demand shocks has been affected by migration. Beaudry et al. (2014) explore differences in labour demand introducing a special set of instruments and local population size as a determinant of employment demand (see also Bartik 2014).
} 
latter cases when we focus on demand for temporary workers. For example, the highest long-run own-price elasticity is found for unskilled-permanent workers located in Pereira $(-1.843)$ while the lowest corresponds to unskilled-temporary in Bogotá $(-0.27)$. Interestingly, the elasticities of permanent skilled workers range between -0.555 (Bogotá) and -1.3 (Manizales). Thus, we claim that heterogeneity of labour demand is reflected the most in the estimated coefficients across cities and draw attention to the implications of this heterogeneity for labour policy design and outcomes. In particular, wage setting across cities should be studied in order to understand whether the higher elasticities respond to rigidities. In addition, some retraining programs might be designed to face the output shocks given the high elasticities found in some regions. ${ }^{5}$

The paper is divided into four sections beyond this introduction. The second section presents some stylized facts about the manufacturing sector. The third section describes the theoretical approach and the empirical model while the fourth presents the results. The fifth section concludes.

\section{The Colombian manufacturing sector}

The structure of the Colombian economy has changed considerably over the past four decades. In the 1960s the manufacturing sector represented over $17 \%$ of GDP, while in 2013 its share was $11.5 \%$ of GDP. The natural decline in the proportions of agriculture and manufacturing in GDP matched the rise in construction, trade, and services.

Still, manufacturing remains as one of the sectors with the greatest number of workers in the economy. It was the fourth largest contributor to employment, with $12.1 \%$, according to the Great Integrated Household Survey (GEIH), after trade (27.4\%), services (19.4\%), and agriculture (17\%). In 2013, the industrial sector accounted for 2.5 million jobs nationally.

Based upon the AMS, this sector is made up of 9158 establishments (681,452 jobs), ${ }^{6}$ located in the nine major cities (Barranquilla, Bogotá, Bucaramanga, Cali, Cartagena, Cúcuta, Manizales, Medellín, and Pereira) and others. ${ }^{7}$ The stylized facts from AMS endorse the heterogeneity identified by Arango et al. (2013). ${ }^{8}$ Around $80 \%$ of

\footnotetext{
${ }^{5}$ Some other policies related to technology and competition go well beyond the limits of this paper.

6 12,683 jobs are excluded as they are generated in small plants (less than 10 employees).

7 A further geographical disaggregation is not possible because of the need to maintain the anonymity of the establishments. Otherwise, the firms would be, in certain cases, easily identified-mainly those located in cities other than Bogotá, Cali, Medellín, and Barranquilla.

8 The GEIH and the AMS differ, as the first includes employment generated by firms with up to five employees (formal and informal).
}

manufacturing employment is concentrated in four cities (Bogotá, Medellín, Cali, and Barranquilla), with Bogotá accounting for about $40 \%$. With the exception of the former and Bucaramanga, the rest of the cities experienced a decline in their employment share since 2000 (Fig. 1).

Six sectors-food and beverages, chemicals, apparel, rubber and plastic, textiles, and minerals-account for $66 \%$ of total employment. ${ }^{9}$ While remaining the largest employment-generating subsectors, their participation in employment varies over time in an unsteady fashion. Chemicals, rubber and plastic, mineral, metals record sizable increments over time while food and textile decline.

Employment generation by subsector varies across cities (see Fig. 2). Barranquilla generates only a few jobs in apparel while Cali does so in textiles. Food is the largest job generator, with $44 \%$ of total employment in Bucaramanga, 35\% in Cartagena, and 30\% in Manizales. Apparel has been an important employer in Pereira, Medellín, and Cali. Plants devoted to production in all six subsectors can be found in a proportionated fashion in Barranquilla, Bogotá, Cali, and Medellín.

Small- and medium-sized establishments populate the Colombian business landscape, including the manufacturing sector. On average, medium-sized manufacturing plants account for $48 \%$ of the total sample, generating $15 \%$ of the employment. ${ }^{10}$ Large and very large plants represent $32 \%$ of establishments and $83 \%$ of the total employment; small plants-21\% of the total-contribute $1.8 \%$ of total employment. Over time, contract modalities in the manufacturing sector have shifted markedly, with the share of open-ended contracts declining from $71 \%$ (2000) to 61\% (2013) in favour of temporary ones. This shift occurred in almost all subsectors, while its intensity has varied (see Fig. 3). For example, the leather subsector, which in 2000 had about $55 \%$ of workers with openended contracts, at the end of the sample period had only $38 \%$. According to AMS, open-ended (permanent) contracts are those that provide direct employment at a firm without a specific end date. The firm recruits temporary staff for specific tasks on a defined-term contract, with established remuneration, including outsourced labour.

Temporary contracts show some advantages (Kaufman and Hotchkiss 2006, p. 302-303). First, they are less expensive since they offer fewer fringe benefits such as

\footnotetext{
${ }^{9}$ If we add metals and furniture, total employment corresponds to $76.7 \%$ of the sample in 2013.

${ }^{10}$ In this study, small-sized establishments are those that employ 10 people or less, medium-sized between 11 and 50, large between 51 and 500, and very large more than 500 . This size definition allows sufficient degrees of freedom for estimation purposes. Kanbur and Venables (2005) use similar categories.
} 


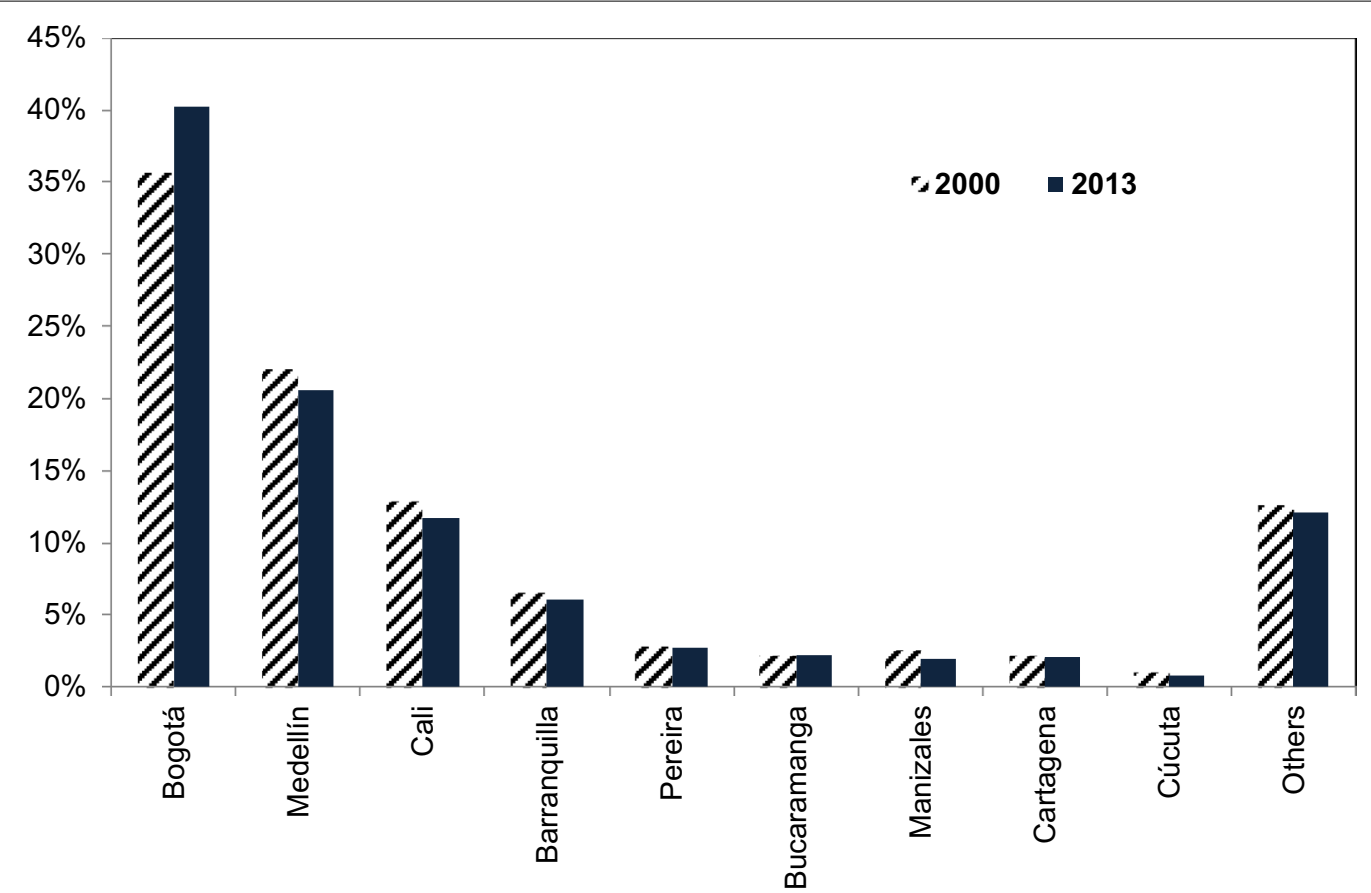

Fig. 1 Contribution to employment of manufacturing subsector by city (\% of total) (Source Dane-AMS and authors' calculations)



Fig. 2 Employment generation by subsector and city, 2013 (Source Dane-AMS and authors' calculations) 


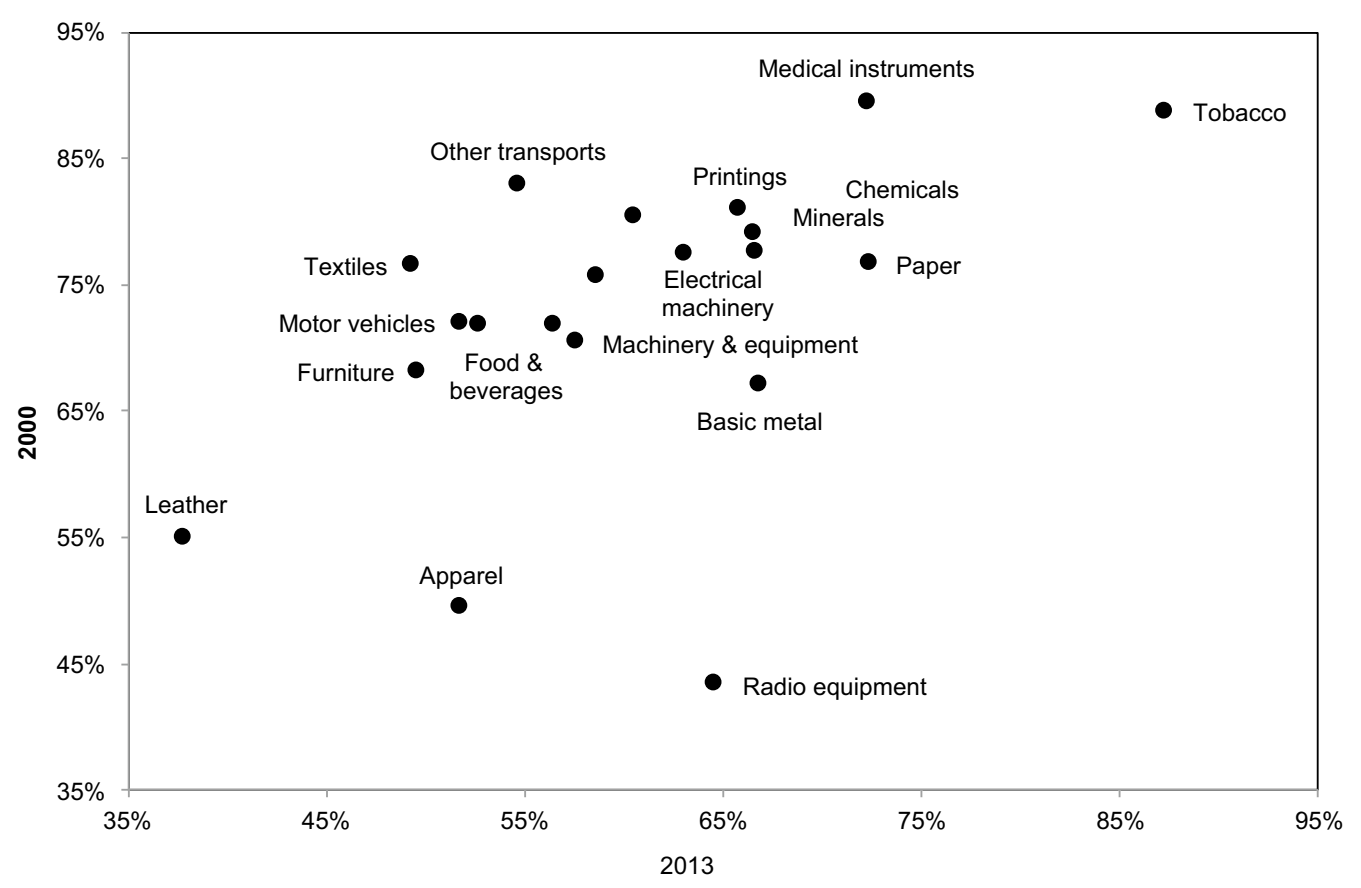

Fig. 3 Permanent (open-ended) contracts by subsector in 2000 and 2013. Proportion of total employment (Source Dane-AMS and authors' calculations)

vacations and health insurance. ${ }^{11}$ Until 2011, these payments accounted for nearly $60 \%$ of wages. ${ }^{12}$ In second place, temporary workers are a more variable input than regular employees. As a result, the establishments can let

\footnotetext{
${ }^{11}$ In Colombia, the costs of open-ended contracts are higher than for fixedterm contracts. Workers with fixed-term contracts can be fired at any time without cost, while workers with open-ended contracts must be paid a dismissal payment. For example, workers with a wage between 1- and 10 monthly minimum wages will receive compensation of 30 days if their tenure is less than 1 year with an extra 20 days for each additional year (Article 64. Labour Code); for workers with wages higher than ten minimum wages, the compensation amounts to 20 days and 15 days for each additional year. Workers with fixed-term contracts receive no additional payments beyond the monthly salary at the end of the contract. In stark contrast, open-ended contracts come with 15 days paid vacations per year, a contribution of $12.5 \%$ of monthly pay for health insurance, a contribution of $16 \%$ to the general pension system, and a pay of half-month's wage at the end of the year. With regard to employment protection, the contracts of permanent workers do not define an end date while fixed-term contracts signed by temporary workers do. These must be written for up to a maximum of 3 years, renewable (Articles 45 and 46 of the Labour Code). As stated in Castellani et al. (2017), "...firms in Colombia can also hire workers through a temporary work agency for services required on an occasional, accidental, or transitory basis, to replace workers who are on vacation, maternity leave, or sick leave, to handle an increase in production, transportation, sales of goods, stationary periods of harvest, and service delivery. These contracts can last no longer than 6 months and are renewable for no longer than six additional months. Finally, workers can be hired through associative employment cooperatives, generating contracts for which there are no mandatory non-wage labour costs. This type of contract is also fixed-term". Finally, unionization in Colombia is rather low, with only $4.6 \%$ of all workers belonging to a union (Dinero 2016); for Fedesarrollo (2017), based on OECD estimates, the rate is $9.2 \%$.

12 The 2012 tax reform, among other things, reduced non-wage labour costs by $13.5 \%$ points.
}

them go when they are no longer needed. This introduces segmentation into the labour force: permanent and temporary workers. ${ }^{13}$

Between 2000 and 2013, the proportion of open-ended contracts among skilled workers ${ }^{14}$ fell sharply in subsectors such as textiles, rubber and plastic, food and beverages, chemicals, and furniture. Unskilled workers with these types of contracts were substituted at a higher rate. In the apparel subsector, the proportion of unskilled employees with open-ended contracts as a percentage of total unskilled employment declined by almost half, from 66 to $37 \%$. In textiles, this proportion changed from 69 to 45\%. Cúcuta, Bucaramanga, and Barranquilla witnessed the largest switch to temporary contracts.

More flexible contract modalities coincide with a broader share of skilled labour force throughout the industry. The largest increases in the skill-content of production take place in chemicals, furniture, and apparel. Chemicals, rubber and plastic, and food and beverages

\footnotetext{
${ }^{13}$ According to Castellani et al. (2017), Colombia is characterized by a dual market where workers are entitled to different kinds of employment protection depending on the contract they hold. These authors find that workers with fixed-term contracts contribute less to the firms' labour productivity than workers with open-ended contracts (see also Lisi and Malo 2017).

${ }^{14}$ Based on the AMS definition, skilled workers include professionals, technicians, and specialists such as mechanical, chemical, industrial, electrical, mining, and petroleum engineers, etc. Unskilled workers are involved in activities such as manufacturing, processing, assembly, installation, maintenance, inspection, storage, packing, loading, and unloading.
} 
show the highest ratios of skilled to total workers while apparel, furniture and textiles show the smallest ones. Minerals is the only subsector where no changes occur. By cities, Cartagena, Cali and Barranquilla have the highest proportion of skilled workers whereas Cúcuta, Pereira, and Bucaramanga use the smallest proportion. Barranquilla, Manizales and Cali doubled the proportion of skilled labour over time.

The food and beverages, chemicals, and minerals subsectors exhibit the highest labour productivity, while apparel generates the lowest output per worker among the sectors that contribute most to employment. This subsector also has a low real wage and capital endowment per worker. Apparently, without further controls, the higher the capital endowment per worker, the higher the real wage.

\section{Theoretical approach and empirical model}

Labour demand theory sets out the variables considered by firms to hire or dismiss employees, such as product demand, labour and other costs (capital, energy, etc.), technology, taxes, and subsidies, among others. Within a static framework of the competitive model, the conditional labour demand is obtained by minimizing the total costs subject to a given level of production and depends on product demand, technology, and relative factor prices. Thus, if there is a change in the latter, everything else remaining constant, labour and capital will be combined in different proportions since they are substitutable. ${ }^{15}$ The demand for these two factors will depend on relative prices and production levels; that is: $l(r / w, y, A ; \alpha)$ and $k(w / r, y, A ; \alpha)$, where $w, r, y, A$ and $\alpha$ are real wages, ${ }^{16}$ real rental prices of capital, output, technology and technical parameters of the production function. The unconditional factor demands, derived from the utility maximization process, take the form: $l(w, r, A ; \alpha)$ and $k(w, r, A ; \alpha)$.

However, given the presence of adjustment costs generated by firms' desires to reach a certain equilibrium level of labour in the production process, and uncertainty within a dynamic context, factor demand turns out to be different from the above specifications (see Hamermesh 1993; Cahuc et al. 2004; Wickens and Princeton University Press 2011). The framework we use to address the estimation of the labour demand includes quadratic and symmetric adjustment costs. Thus, the firm maximizes: where $E_{t}$ represents the expectations operator, $r_{t}$ the interest rate, $l_{t}$ the number of employees, and $A_{t}$ shocks of different nature that affects the firm's product supply. From the first-order conditions:

$$
\Delta l_{t+j}=E_{t}\left\{\frac{F_{l}\left(l_{t+j}, A_{t+j}\right)-w_{t+j}}{a}+\frac{\Delta l_{t+j+1}}{(1+r)}\right\} \quad j=0,1, . .
$$

By replacing forward, this expression can be rewritten as:

$$
\Delta l_{t+j}=E_{t}\left\{\sum_{j=0}^{\infty} \frac{F_{l}\left(l_{t+j}, A_{t+j}\right)-w_{t+j}}{a(1+r)^{j}}\right\}
$$

Thus, within this partial equilibrium approach, if the present value of the marginal product of labour is greater than the present value of wages, the number of employees will increase. Assuming rational expectations, the model (see Sargent 1978; Nickel 1984; Hamermesh 1993; Cahuc et al. 2004) can be written as

$$
l_{t}=\lambda l_{t-1}+\sum_{m=1}^{K} \sum_{j=0}^{J_{m}} \mu_{m j} X_{m, t-j}
$$

By using the notation of Hamermesh (1993, Chapter 7), the empirical model turns into

$$
l_{i, t}=\lambda l_{i, t-1}+\sum_{m=1}^{K} \sum_{j=0}^{J_{m}} \mu_{m, j} X_{i, m, t-j}+\omega_{i, t}
$$

where index $i$ accounts for plant $i, X_{i, m, t-j}$ is the vector of observable variables including the average real wage paid by the establishment, the added value ${ }^{17}$ of the plant, the TFP indicator, etc.; $\mu_{m, j}$ is the vector of coefficients to be estimated, and $\omega_{i, t}$ is the residual term. To have information about the adjustment costs, the empirical model holds just one autoregressive element (Hamermesh 1993), which can be separated from the expectations of remaining variables based on past realizations.

Potentially, the residual term is the sum of different elements: $\omega_{i, t}=\eta_{i}+v_{i, t}+\varepsilon_{i, t}$. The first component, $\eta_{i}$, accounts for unobserved heterogeneity directly linked to

$$
\pi_{t}=E_{t}\left\{\sum_{j=0}^{\infty}(1+r)^{-j}\left[F\left(l_{t+j}, A_{t+j}\right)-w_{t+j} l_{t+j}-0.5 a\left(l_{t+j}-l_{t+j-1}\right)^{2}\right]\right\}
$$

\footnotetext{
${ }^{15}$ If capital, $k$, and labour, $l$, are both strictly required for the production process in given proportions, then they are said to be complementary.

16 Permanent worker wages include social contributions. Temporary worker wages correspond to the total employment cost for the firm.
}

\footnotetext{
${ }^{17}$ In the AMS, the added value is calculated as the difference between gross production and intermediate consumption.
} 
plant characteristics other than the price of inputs and usual determinants of labour demand (see Roberts and Skoufias 1997). The list of plausible candidates includes special properties of output, the relative advantages to combine inputs in the production process, etc. The second element, $v_{i, t}$, can be related to shocks to the supply of labour specific to the production of the plant, etc. These first two elements of the unobserved heterogeneity could eventually be correlated to the output of the plant as well as the wage $\left[E\left(\eta_{i} \mid X_{i, m, t}\right) \neq 0\right]$ and $\left[E\left(v_{i, t} \mid X_{i, m, t}\right) \neq 0\right]$; as a result, the respective coefficients would admittedly be biased upwards. The third element, $\varepsilon_{i, t}$, is a well-behaved random component.

To address the potential endogeneity, the reverse causality of real wage and the establishment output, as well as measurement errors of the former, intrinsic to the way in which AMS reports information about wages (see below), we use instrumental variables and some moment conditions. Arellano and Bover (1995) and Blundell and Bond (1998) indicate that lagged levels are often rather poor instruments for first differenced variables, especially if the variables are close to a random walk. Thus, the paper adopts the Blundell and Bond (1998) GMM estimator where both lagged levels and lagged first differences can be combined as instruments to improve the efficiency of the estimator. As the standard errors of the two-step system GMM estimator present downward bias, the Windmeijer (2005) correction is also used.

The paper combines skilled and unskilled, permanent (open-ended) and temporary employment, and explores the regional, sector, and size dimensions of labour demand heterogeneity. The resulting estimations consist of long-run elasticities for (i) each of the nine major cities (Barranquilla, Bogotá, Bucaramanga, Cali, Cartagena, Cúcuta, Manizales, Medellín, and Pereira) and "others"; (ii) the largest employment-generating subsectors (food and beverages, chemicals, apparel, rubber and plastic, textiles, mineral, metals, and furniture) and plant sizes (medium, large, and very large).

To take advantage of the panel structure of the AMS, the paper uses information at the establishment level between 2000 and 2013. The smallest number of plants of our unbalanced panel is 6801 in 2003 while the highest is 9867 in 2010. ${ }^{18}$ The number of plants was 9158 in 2013, the last year of the sample.

The empirical specification sets the demand for labour in terms of its own lag, contemporary and lagged values of (average) real wages, value-added of the firm, TFP,

\footnotetext{
${ }^{18}$ When the dependent variable is zero, the establishment does not demand that type of labour; such case is excluded from the regression.
}

the real minimum wage, ${ }^{19}$ energy prices, and the real interest rate. ${ }^{20}$ The specification also includes the contemporary value of the depreciation rate. ${ }^{21}$ Average real wage, minimum wage, added value starting at lag three as well as year dummies are used as instruments. Most of the results below are focused on long-run elasticities computed as: $\epsilon_{j}=\left(\mu_{m, 0}+\mu_{m, 1}\right) /(1-\lambda)$, where $m$ corresponds to the real wage, output, and TFP, respectively. Thus, we focus on neither other variables different from these three nor short-run coefficients.

As the AMS does not have information about individual real wages, these are computed by dividing the payroll in real terms ${ }^{22}$ among the number of skilled and unskilled workers. Output corresponds to the total value-added in each plant, the energy prices are those paid by the establishment for this concept, and the depreciation rate is the annual value established as replacement for the spoilage, use, or obsolescence of fixed assets adjusted for inflation during their useful life as a proportion of total assets. TFP is computed by using the Levinsohn and Petrin (2003) algorithm. Finally, the real interest rate corresponds to ordinary and preferential interest rates, ${ }^{23}$ since the real rental price of each plant is not available. Except for the real interest rates and the depreciation rate, all variables are expressed in logs.

\section{Results $^{24}$}

Table 1 shows own real price, output, and TFP long-run elasticities under conditional and unconditional specifications of labour demand for skilled and unskilled workers. ${ }^{25}$ In column (1) we observe that wage elasticities of

\footnotetext{
19 The use of the minimum wage, that changes annually, prevents us from using the time-fixed effects. These variables altogether produce some nonsense elasticities. Thus, we prefer the specification with the level of minimum wage.

20 The conditional version of labour demand with substitutes includes the contemporary and lagged values of the other types of workers. For instance, in the specification of skill permanent we included the skilled temporary as well as unskilled both permanent and temporary. These estimations are intended to address, from another point of view, labour market segmentation within the industrial establishments. The first way we address it is by estimating demand for each type of workers.

21 According to the AMS, the depreciation corresponds the annual value set as replacement for the deterioration, use, or obsolescence of the firm fixed assets during their lifetime.

22 Local CPI's are used to obtain variables in real terms.

23 The difference between these two interest rates is the size of the plant. Preferential is the interest rate on loans granted to large and very large establishments (about 32\% of the plants) while the ordinary corresponds to the interest rate of credits requested by medium size establishments.

24 Estimations include neither small size establishments $(<10$ employees) nor the residual city category called "others", although both were included in the descriptive statistics.

25 Bresson et al. (1992) previously conducted analyses on skilled and unskilled workers.
} 
skilled $(-0.591)$ and unskilled workers $(-0.415)$ are both significant. Contrary to existing literature, skilled employment shows a larger sensitivity to its own price (see Litcher et al. 2014 and, for the case of Colombia, Roberts and Skoufias 1997). ${ }^{26}$ When estimations take into account contract modalities, to provide insights on the contracting duality of the Colombian labour market, the long-run real wage elasticity of open-ended contracts workers is larger than temporary, irrespective of their skills. Increased flexibility in the labour market institutions and progress in labour intermediation $^{27}$ over the sample period might explain this larger response. Demand for unskilled workers is, in general, more responsive than skilled ones, in line with previous research. Moreover, under the conditional specification, temporary unskilled workers show an elasticity of -0.438 and skilled workers of -0.256 . Similarly, the elasticity to the real wage of demand for unskilled workers with open-ended contracts is -1.109 and -0.682 for skilled permanent workers. ${ }^{28}$

Long-run elasticity to output is higher than real wage elasticity as in previous studies. Permanent workers (0.949-skilled and 1.198-unskilled) show larger responsiveness to output than do temporary ones (0.710-skilled and 0.760-unskilled). However, demand for skilled (1.122) is more sensitive than for unskilled workers (1.051). The theory predicts a negative sign of the response to TFP in the case of conditional labour demand and a positive one for unconditional demand. These predictions match the estimates for both types of workers, with a larger response for permanent employees. The respective elasticities, corresponding to the conditional demand specification, are -0.773 and -0.621 for skilled workers and -1.043 and -0.73 for unskilled ones. Demand for skilled workers, regardless of contract modalities, displays lower TFP elasticity and more resilience to technology changes.

The inclusion of other types of workers in the labour demand specification, ${ }^{29}$ differentiated by skills and contract modalities, affects the long-run elasticities mainly for unskilled temporary employees [see column (2)].

\footnotetext{
${ }^{26}$ Judzik 2015 finds differences in elasticities between the United States, Germany, and Sweden, which are reasonable given the differences in the norms, regulations and nature and intensity of shocks these economies have faced during the sample period.

27 Over the previous decade, some matching platforms (e.g., "elempleo. com") were developed and supported labour market performance.

${ }^{28}$ In general, according to the Hansen test, the set of instruments is accurate and the Ar2 test shows that the errors do not exhibit autocorrelation of order two.

29 These specifications include the current and previous stock of other workers within the plant. We prefer this specification rather than including just the wage of other types of workers to include other information on the labour force not covered by the real wage, such as labour protection.
}

Demand for skilled temporary workers increases the demand for unskilled ones. A clear substitution can be observed in the case of skilled permanent workers where an increase in the stock of skilled temporary reduces its demand. Thus, linked to segmentation, there seems to be some evidence of strategic composition of the labour force in the industrial sector.

Under the unconditional specification [(column (3)], the own-price elasticity is significant for both skilled and unskilled permanent workers. At the same time, TFP elasticity is significant only for skilled workers and has in the three cases the right sign; while TFP might not be a long-run determinant of unskilled demand, another possible interpretation is that this labour demand specification might not be appropriate for unskilled labour.

The empirical specification allows us estimating the speed of adjustment of labour demand (halfway or halflife of the adjustment) to shocks in output or factor prices. The median length is computed by solving for $t^{*}$ the expression $\lambda^{t^{*}}=0.5$. Under the conditional specification, the halfway ranks between 0.61 and 1.27 years (Fig. 4), corresponding to skilled temporary workers and unskilled permanent ones, respectively, pointing at a shorter adjustment period for higher level of skills and more flexible contracts. These results are consistent with existing estimates using annual data which show halfways of 5.5 quarters (Hamermesh 1993, p. 253).

The heterogeneity between skilled and unskilled workers had already been analyzed by Roberts and Skoufias (1997). Nevertheless, the differences between open-ended and temporary contracts have been examined less in the study of manufacturing sector labour demand. These results call for the authorities to pay attention to the long-run elasticities of each type of worker when forming expectations about the effects of shocks. In the next three sections, we go beyond skills and contract modalities, to regional, sectoral, and size heterogeneities. To this end, given the consistency of results with the theory, we focus only on the conditional labour demand. ${ }^{30}$

\subsection{Regional heterogeneity}

As mentioned before, labour market outcomes present disparities across metropolitan areas in Colombia. The elasticities are estimated across the nine major cities to verify regional labour market heterogeneity. Results indicate that, besides Cartagena and Cúcuta, whose elasticities are not statistically significant, real wage longrun elasticities of permanent skilled workers (Fig. 5a)

\footnotetext{
30 The unconditional demand for labour assumes that the firm can choose the level of production that maximizes the benefits.
} 
Table 1 Long-run labour demand elasticities (2000-2013). Source Dane-AMS; authors' calculations

\begin{tabular}{|c|c|c|c|}
\hline Specification & Conditional (1) & Conditional with substitutes ( 2 ) & Unconditional (3) \\
\hline \multicolumn{4}{|l|}{ Skilled workers } \\
\hline Own-price & $-0.591^{* * *}$ & $-0.628^{* * *}$ & $-0.316^{* * *}$ \\
\hline Output & $1.122^{* * *}$ & $1.153^{* * *}$ & \\
\hline TFP & $-1.016^{* * *}$ & $-0.936^{* * *}$ & $0.326^{*}$ \\
\hline Unskilled permanent & & 0.009 & \\
\hline Unskilled temporary & & $0.212^{* *}$ & \\
\hline No. observations (plants) & 14,579 & 7979 & 14,579 \\
\hline Hansen test ( $p$-value) & 0.102 & 0.333 & 0.808 \\
\hline Ar2 (p-value) & 0.540 & 0.457 & 0.969 \\
\hline \multicolumn{4}{|l|}{ Skilled permanent workers } \\
\hline Own-price & $-0.682^{* * *}$ & $-0.647^{* * *}$ & $-0.517^{* * *}$ \\
\hline Output & $0.949^{* * *}$ & $1.206^{* * *}$ & \\
\hline TFP & $-0.773^{* * *}$ & $-1.026^{* * *}$ & $0.753^{* * *}$ \\
\hline Skilled temporary & & $-0.318^{* * *}$ & \\
\hline Unskilled permanent & & -0.075 & \\
\hline Unskilled temporary & & $0.335^{*}$ & \\
\hline No. observations (plants) & 13,062 & 2696 & 13,062 \\
\hline Hansen test ( $p$-value) & 0.213 & 0.469 & 0.514 \\
\hline Ar2 (p-value) & 0.700 & 0.741 & 0.398 \\
\hline \multicolumn{4}{|l|}{ Skilled temporary workers } \\
\hline Own-price & $-0.256^{* * *}$ & $-0.261^{* * *}$ & $-0.251^{* * *}$ \\
\hline Output & $0.710^{* * *}$ & $0.747^{* * *}$ & \\
\hline TFP & $-0.621^{* * *}$ & $-0.617^{* * *}$ & $0.590^{*}$ \\
\hline Skilled permanent & & 0.053 & \\
\hline Unskilled permanent & & $0.326^{* * *}$ & \\
\hline Unskilled temporary & & -0.204 & \\
\hline No. observations (plants) & 4477 & 2696 & 4477 \\
\hline Hansen test ( $p$-value) & 0.467 & 0.420 & 0.761 \\
\hline Ar2 (p-value) & 0.443 & 0.255 & 0.464 \\
\hline \multicolumn{4}{|l|}{ Unskilled workers } \\
\hline Own-price & $-0.415^{* * *}$ & $-0.702^{* * *}$ & 0.074 \\
\hline Output & $1.051^{* * *}$ & $1.179^{* * *}$ & \\
\hline TFP & $-0.951^{* * *}$ & $-1.103^{* * *}$ & 0.261 \\
\hline Skilled permanent & & -0.028 & \\
\hline Skilled temporary & & $0.079^{* *}$ & \\
\hline No. observations (plants) & 20,470 & 3114 & 20,470 \\
\hline Hansen test ( $p$-value) & $1.21 \mathrm{e}-05$ & 0.232 & 0.000113 \\
\hline Ar2 (p-value) & 0.618 & 0.024 & 0.346 \\
\hline \multicolumn{4}{|l|}{ Unskilled permanent workers } \\
\hline Own-price & $-1.109^{* * *}$ & $-1.082^{* * *}$ & $-0.865^{* * *}$ \\
\hline Output & $1.198^{* * *}$ & $1.242^{* * *}$ & \\
\hline TFP & $-1.043^{* * *}$ & $-1.071^{* * *}$ & 0.429 \\
\hline Skilled permanent & & -0.049 & \\
\hline Skilled temporary & & 0.065 & \\
\hline Unskilled temporary & & $0.351^{* * *}$ & \\
\hline No. observations (plants) & 17,502 & 2696 & 17,502 \\
\hline Hansen test ( $p$-value) & 0.637 & 0.350 & 0.589 \\
\hline Ar2 (p-value) & 0.339 & 0.677 & 0.513 \\
\hline
\end{tabular}


Table 1 (continued)

\begin{tabular}{llll}
\hline Specification & Conditional (1) & Conditional with substitutes (2) & Unconditional (3) \\
\hline Unskilled temporary workers & & \\
Own-price & $-0.438^{* * *}$ & $-0.683^{* * *}$ & -0.107 \\
Output & $0.760^{* * *}$ & $1.058^{* * *}$ & 0.223 \\
TFP & $-0.730^{* * *}$ & $-1.047^{* * *}$ & -0.197 \\
Skilled permanent & & $0.415^{* * *}$ & $0.200^{* *}$ \\
Skilled temporary & & 2696 & 12,579 \\
Unskilled permanent & 12,579 & 0.291 & 0.00401 \\
No. observations (plants) & 0.000153 & 0.489 & 0.00624 \\
Hansen test (p-value) & 0.702 & & \\
Ar2 (p-value) & & & \\
\hline
\end{tabular}

${ }^{*},{ }^{* *},{ }^{* * *}$ Correspond to $10 \%, 5 \%$ and $1 \%$ level of significance, respectively. Hansen test refers to the accuracy of the set of instruments; the Ar 2 test shows that the errors do not exhibit autocorrelation of order two

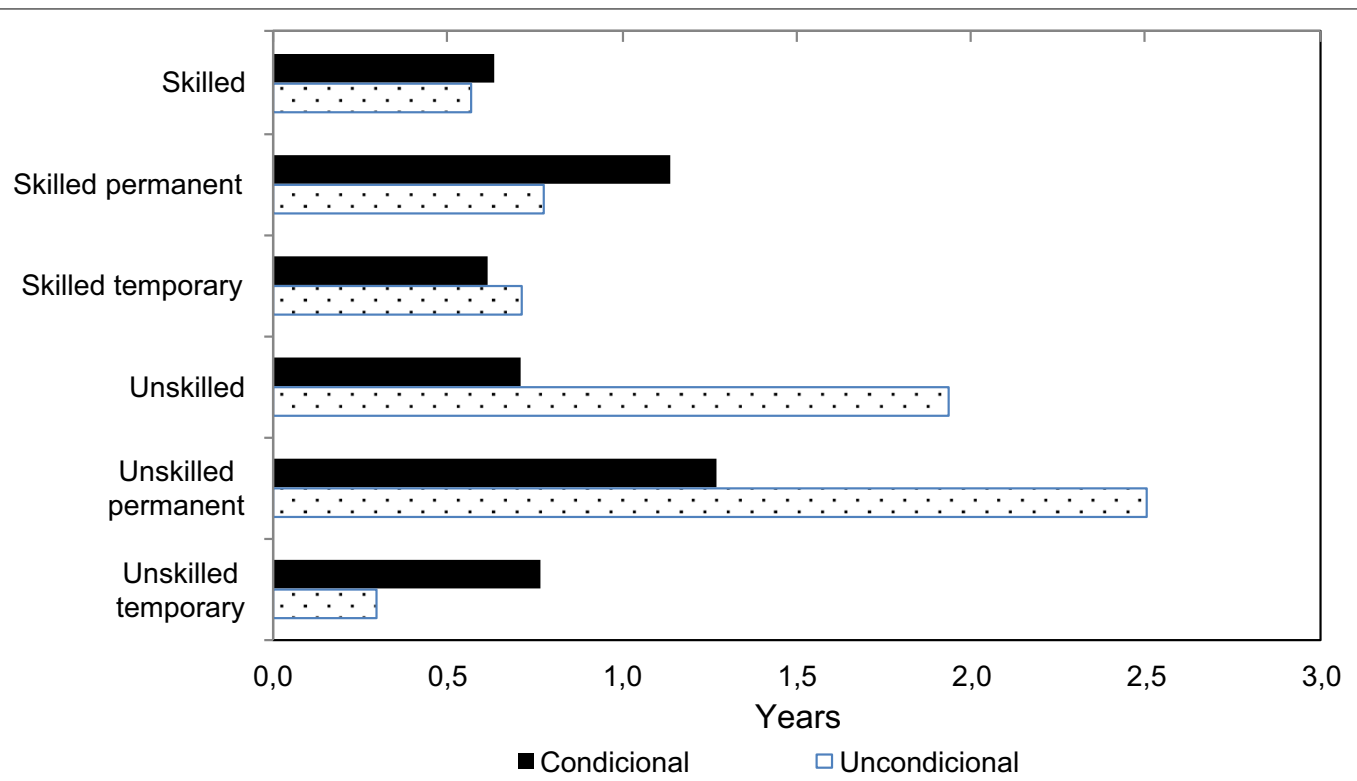

Fig. 4 Halfway of labour demand adjustments (2000-2013) (Source Dane-AMS and authors' calculations)

are negative and significant and range between -1.3 (Manizales) and -0.632 (Medellín). By focusing on this analysis, we see that, at least partially, the disparities of employment performance across cities are related to the size of elasticities; the remaining behaviour corresponds to differences in the type, magnitude (intensity), and duration of the shocks to each particular region.

In the case of skilled workers with temporary contracts (see Fig. 5b), the highest own-price elasticity corresponds to Manizales $(-1.061)$. For permanent unskilled workers (see Fig. 5c), the greatest value is found in Pereira $(-1.843)$ and the least in Barranquilla $(-0.983)$. In the case of unskilled temporary workers (see Fig. $5 \mathrm{~d}$ ), the elasticity varies between -0.27 (Bogotá) and -0.58
(Barranquilla), and only these two cities, together with Medellín and Pereira, hold significant long-run elasticities. Consistent with Fig. 5, the geographic breakdown confirms that demand for temporary workers, both skilled and unskilled, is less responsive to its own price than permanent ones. To achieve better outcomes, all agents involved in the labour market should consider this heterogeneity. For example, if, ceteris paribus, there is a shock that increases real wages in Pereira, ${ }^{31}$ given

\footnotetext{
${ }^{31}$ Before 2006, Pereira underwent a strong reduction in the rate of participation related to the stream of remittances from Spain and the United states. This labour supply shock, well documented in Colombia (see, for example, Arango and de la Mata 2015), might produce this kind of reaction in real wages.
} 
a Permanent skilled

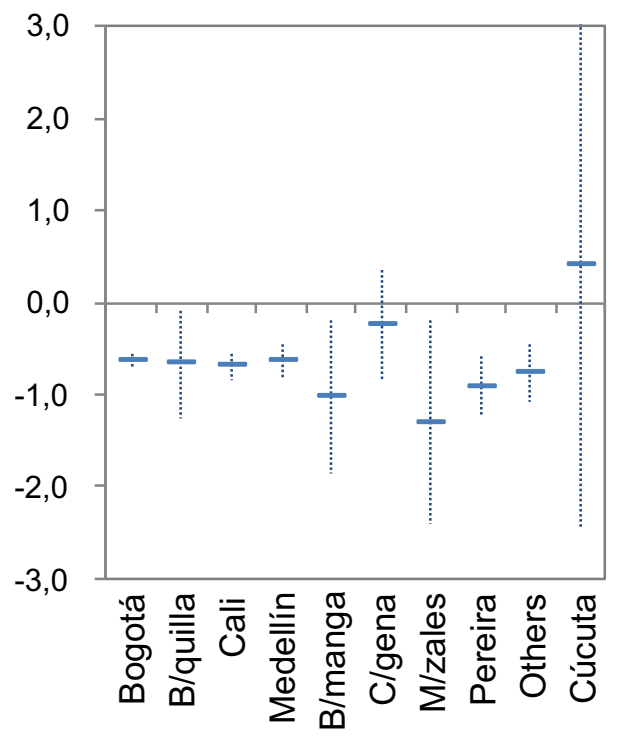

c Permanent unskilled

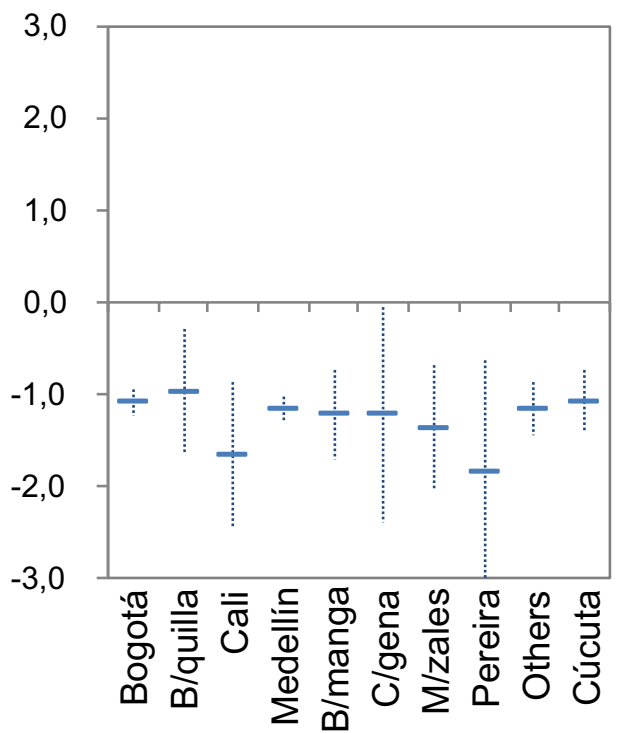

b Temporary skilled

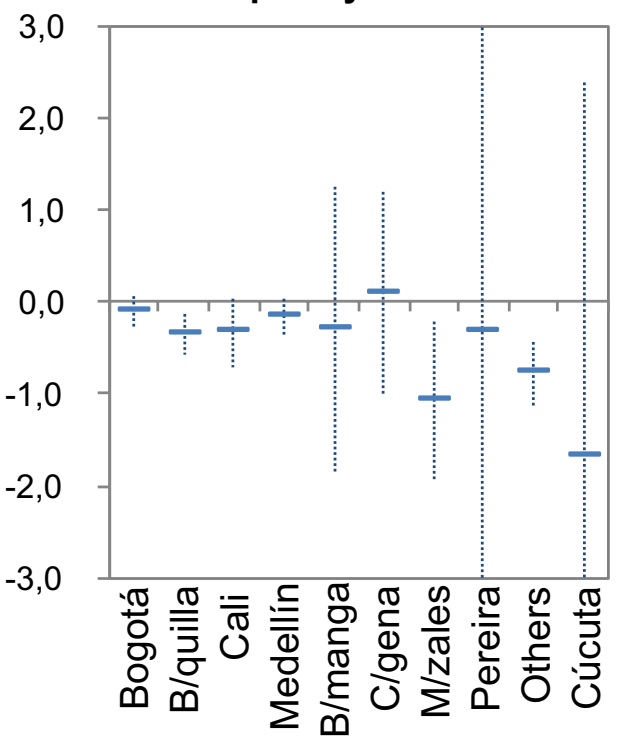

d Temporary unskilled

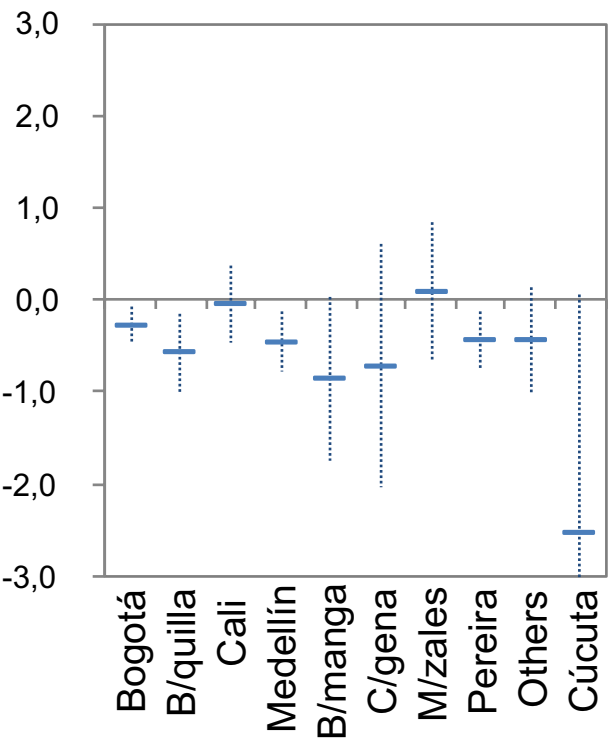

Fig. 5 Long-run own-price elasticity of conditional labour demand (2000-2013). 95\% confidence intervals (Source Dane-AMS and authors' calculations)

the sizable elasticity for unskilled workers, there will be employment destruction. By contrast, if the shock reduces the real wage, employment will rise. However, high volatility in the labour market is not desirable. Instead, to avoid adverse employment outcomes after the shocks, wages should be more flexible in that city. ${ }^{32}$

\footnotetext{
${ }^{32}$ The same policy recommendation would apply for Manizales, Bucaramanga, and Cali if we observe the high own-price elasticity for permanent skilled workers for the former two and for permanent unskilled in the latter.
}

Alternatively, the cost of permanent unskilled labour should be lowered to have a response similar to that of temporary labour, for which the elasticity is -0.44 . In other words, the duality of the labour market should be reduced. However, this policy prescription is not necessarily the same if we observe the unskilled temporary workers in Bogotá where the response of labour demand is much smaller and the shock can be absorbed without a high risk of job destruction. 
a Permanent skilled

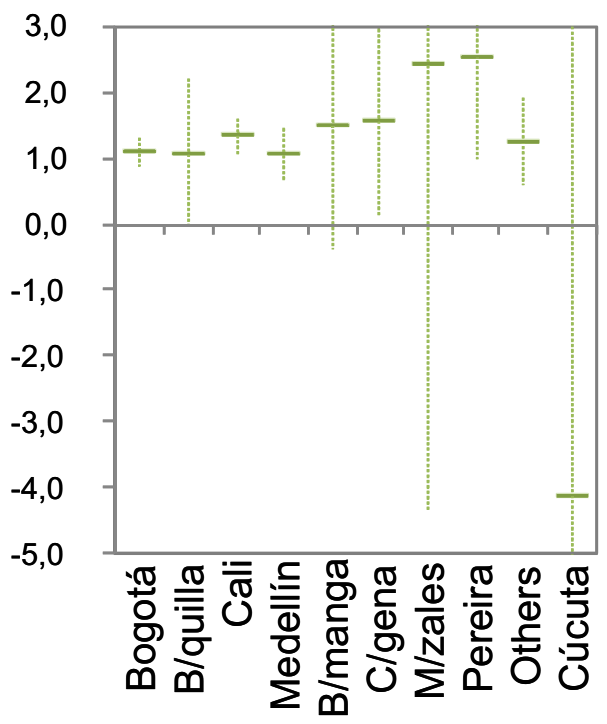

C Permanent unskilled

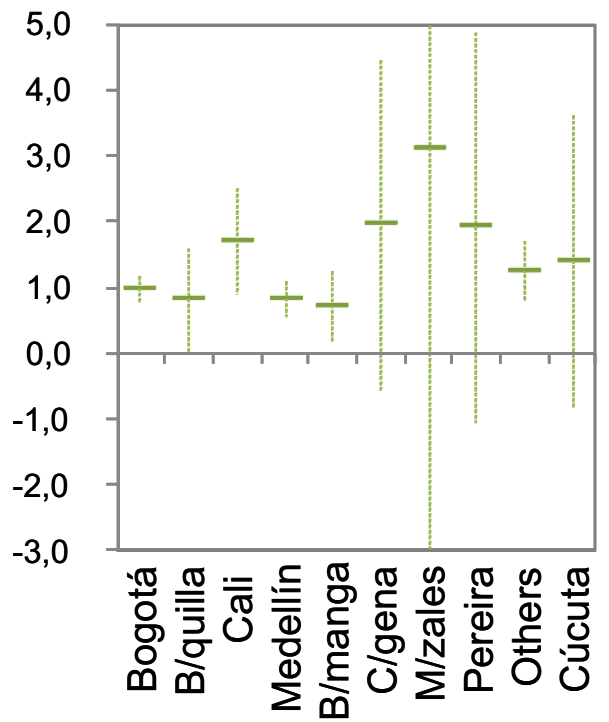

b Temporary skilled

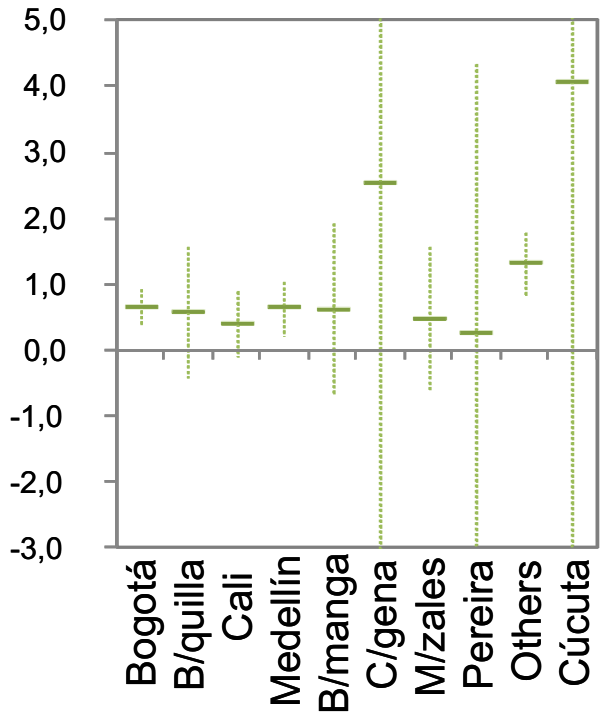

d Temporary unskilled

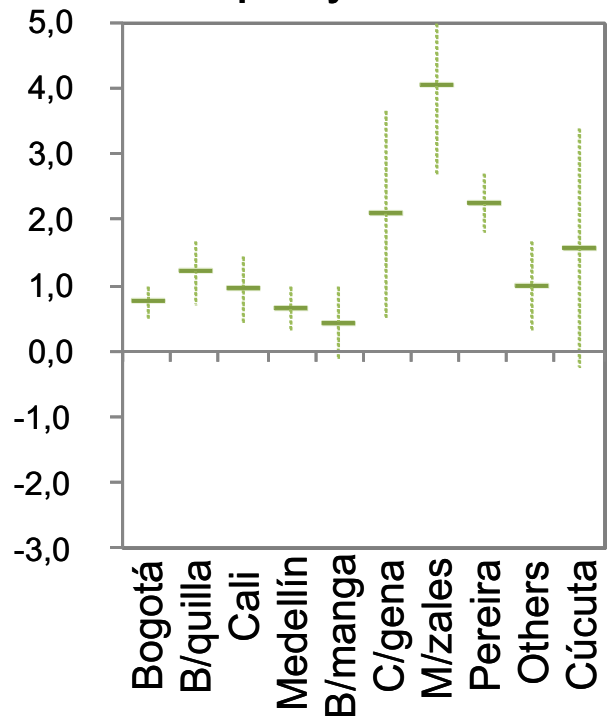

Fig. 6 Long-run output elasticity of conditional labour demand (2000-2013). 95\% confidence intervals (Source Dane-AMS and authors' calculations)

Output elasticities in all cities except Cúcuta are all positive (Fig. 6). However, significant long-run reactions of permanent skilled labour to output movements (Fig. 6) are obtained in plants in Bogotá, Cali, Cartagena, Medellín, and Pereira. In the case of temporary skilled workers (see Fig. 6b), only long-run elasticities corresponding to Bogotá and Medellín are significant.

As we can observe in Fig. 6c, the demand for permanent unskilled employees is responsive to output in the long run in Cali (1.702), "other cities" (1.241), Bogotá (0.987), Medellín (0.833), Barranquilla (0.814), and Bucaramanga (0.723). The lowest estimate for temporary unskilled workers (Fig. 6d) is found in Medellín (0.619) and the highest in Manizales (4.047). Based on all the output elasticities, we could assert that establishments located in Bogotá, Barranquilla, Cali, and Medellín, have production functions whose homogeneity is not very far from unity. However, the interesting cases of Manizales and Pereira do not have clearly defined homogeneity. ${ }^{33}$

\footnotetext{
33 This is unfortunate since, based on the four laws of derived demand, we might suggest that given the high values of the own-price elasticity exhibited by establishments in Manizales, the output market in this city is more competitive than in others. However, this assertion requires a well-defined homogeneity of the production function.
} 
Elasticities to TFP are negative in most cases as predicted by the theory under the conditional specification (not shown).

The length of adjustment to shocks we compute from the estimates (not shown) is greater for unskilled and permanent workers. Thus, for these two types of workers, the persistence of labour demand is higher. This adjustment period is an average given the different shocks faced by plants during the sample period. Bogotá consistently adjusts at a higher speed than the other cities across both skills and contract modalities.

The heterogeneity of conditional labour demand determinants seems a prevalent characteristic of the manufacturing sector in Colombia. The hypothesis that the difference between the coefficients of each pair of cities is equal to zero is checked by means of the $t$ test (Kmenta 1971, p. 419):

$$
t=\left(\mu_{m}^{y}-\mu_{m}^{z}\right) / \sqrt{v_{\mu_{m}^{y}} \sigma_{\mu_{m}^{y}}^{2}+v_{\mu_{m}^{z}} \sigma_{\mu_{m}^{z}}^{2} /\left(v_{\mu_{m}^{y}}+v_{\mu_{m}^{z}}\right)}
$$

where $\sigma_{\mu_{m}^{y}}^{2}$ and $v_{\mu_{m}^{y}}^{y}$ corresponds, respectively, to the variance of the coefficient $\mu_{m}^{y}$ and the degrees of freedom and assumes that the populations (number of establishments) located in two different cities, $y$ and $z$, are independent, which eliminates the covariance term that customarily is present within the square root. We adopt this test instead of Welch's (1947), $t=\left(\mu_{m}^{y}-\mu_{m}^{z}\right) / \sqrt{\sigma_{\mu_{m}^{y}}^{2} / n^{y}+\sigma_{\mu_{m}^{z}}^{2} / n^{z}}$ given the tendency of the latter to generate false positives or type I errors (see Sawilowsky 2002); thus, this test would lead us to reject the null hypothesis $\left(H_{0}: \mu_{m}^{y}-\mu_{m}^{z}=0\right)$ even in the case when this is true. In this case, we would be over-predicting the geographical heterogeneity of manufacturing labour demand. We also set aside the test $t=\left(\mu_{m}^{y}-\mu_{m}^{z}\right) / \sqrt{\sigma_{\mu_{m}^{y}}^{2}+\sigma_{\mu_{m}^{z}}^{2}}$ (Lindgreen 1993, p. 115) which gives the same weight to both variances irrespective of the size of populations $x$ and $y$ (for a discussion see Brame et al. 1998).

In Table 2, where we show the result of the test for permanent workers, where $w, y$ and $t f p$ stand for real wage, output, and total factor productivity. The lower part of the matrix (below the diagonal), the label " $\checkmark$ " indicates that the null hypothesis that the long-run wage (output or TFP) elasticities of skilled workers are equal between each pair of cities cannot be rejected at $5 \%$ level of significance. On the other hand, the label " $\mathrm{X}$ " means that the hypothesis can be rejected. The label "-" is used when any or both of the long-run coefficients are not significantly different from zero.

Based on the tests carried out, the null hypothesis that the elasticities of each type of demand for labour are equal for some combinations of cities cannot be rejected while in others it can be. For example, the conditional demand for labour of permanent skilled workers of Pereira is significantly different from that of Bogotá, Cali, and Medellín with respect to real wage, output, and TFP. Differences in long-run elasticities of real wages are also observed between Bogotá and Bucaramanga, and Manizales. As we stated above, these results suggest that some modifications in wage-setting should be introduced in these cities to reduce the relatively high responses when facing shocks that increase the real wage of skilled permanent workers.

The hypothesis that the long-run elasticities of demand for permanent skilled workers are equal in Bogotá and Medellín cannot be rejected at 5\% significance level. In the case of unskilled workers, Pereira shows significant differences with Bogotá, Barranquilla, and Medellín (see the section above the diagonal in Table 2). Again, wagesetting revisions should be carried out in such cities to reduce unnecessary volatility in some labour market outcomes. Importantly, for these types of workers and contracting modalities, Cali and Bogotá exhibit significant differences across the three elasticities.

The heterogeneity of the long-run output elasticity ${ }^{34}$ should be taken into account to promote some re-training for the labour force displaced during an idiosyncratic slump or after a particular shock to a geographic area. This also the case for TFP shocks.

In the case of temporary workers (Table 3), only for Barranquilla and Manizales can we reject the null hypothesis that the own-price elasticity is equal. For unskilled workers (above the main diagonal), Bogotá and Barranquilla show statistical differences in the elasticities with respect to $w, y$ and TFP, while, with respect to the latter two, Bogotá shows differences with Cartagena, Manizales, and Pereira. As in the case of permanent workers, here we also obtain evidence that differences between Bogotá and Medellín are not significant for unskilled workers. Overall, the geographic analysis points to a high heterogeneity, which calls for policies to reduce disparities. Among such policies are versatile retraining programs, changes in the relative labour costs of permanent workers, and wage-setting procedures.

\subsection{Sector heterogeneity}

Disparities of labour demand might also emerge across industrial subsectors. To simplify the analysis, this is restricted to the largest employment-generating ones;

\footnotetext{
${ }^{34}$ This characteristic of labour demand is very important since, given an aggregate demand shock the employment response will vary across regions. This fact, potentially, might induce nonlinearities in Okun's law, at least in this segment of employment.
} 
Table 2 Geographical homogeneity test on conditional labour demand for permanent workers. Source Dane-AMS; authors' calculations

\begin{tabular}{|c|c|c|c|c|c|c|c|c|c|c|c|c|c|c|c|c|c|c|c|c|c|c|c|c|c|c|c|}
\hline \multirow{2}{*}{$\begin{array}{c}\text { Unskilled } \rightarrow \\
\text { Skilled } \downarrow\end{array}$} & \multicolumn{3}{|c|}{ Bogotá } & \multicolumn{3}{|c|}{ Barranquilla } & \multicolumn{3}{|c|}{ Bucaramanga } & \multicolumn{3}{|c|}{ Cali } & \multicolumn{3}{|c|}{ Cartagena } & \multicolumn{3}{|c|}{ Manizales } & \multicolumn{3}{|c|}{ Medellín } & \multicolumn{3}{|c|}{ Pereira } & \multicolumn{3}{|c|}{ Cúcuta } \\
\hline & $w$ & $\boldsymbol{Y}$ & $t f p$ & $w$ & $y$ & $t f p$ & $w$ & $y$ & $t f p$ & $w$ & $\boldsymbol{Y}$ & $t f p$ & $w$ & $Y$ & $t f p$ & $w$ & $y$ & $t f p$ & $w$ & $y$ & $t f p$ & $w$ & $y$ & $t f p$ & $w$ & $\boldsymbol{Y}$ & $t f p$ \\
\hline Bogotá & & & & $\checkmark$ & $\checkmark$ & - & $\checkmark$ & $\mathbf{X}$ & - & $\mathbf{X}$ & $\mathbf{X}$ & $\mathbf{X}$ & $\checkmark$ & - & - & $\mathbf{X}$ & - & - & $\checkmark$ & $\checkmark$ & $\checkmark$ & $\mathbf{X}$ & - & - & $\checkmark$ & - & - \\
\hline Bucaramanga & $\mathbf{X}$ & - & - & $\checkmark$ & - & - & & & & $\checkmark$ & $\mathbf{X}$ & - & $\checkmark$ & - & - & $\checkmark$ & - & - & $\checkmark$ & $\checkmark$ & - & $\checkmark$ & - & - & $\checkmark$ & $\checkmark$ & $\checkmark$ \\
\hline Cali & $\checkmark$ & $\mathbf{X}$ & $\checkmark$ & $\checkmark$ & $\checkmark$ & - & $\checkmark$ & - & - & & & & $\checkmark$ & - & - & $\checkmark$ & - & - & $\mathbf{X}$ & $\mathbf{X}$ & $\mathbf{X}$ & $\checkmark$ & - & - & $\checkmark$ & - & - \\
\hline Cartagena & - & $\mathbf{X}$ & $\checkmark$ & - & $\checkmark$ & - & - & - & - & - & $\checkmark$ & $\checkmark$ & & & & $\checkmark$ & - & - & $\checkmark$ & - & - & $\checkmark$ & - & - & $\checkmark$ & - & - \\
\hline Manizales & $\mathbf{X}$ & - & - & $\checkmark$ & - & - & $\checkmark$ & - & - & $\mathbf{X}$ & - & - & - & - & - & & & & $\checkmark$ & - & - & $\checkmark$ & - & - & $\checkmark$ & - & - \\
\hline Medellín & $\checkmark$ & $\checkmark$ & $\checkmark$ & $\checkmark$ & $\checkmark$ & - & $\mathbf{X}$ & - & - & $\checkmark$ & $\checkmark$ & $\mathbf{X}$ & - & $\checkmark$ & $\mathbf{X}$ & $\mathbf{X}$ & - & - & & & & $\mathbf{X}$ & - & - & $\checkmark$ & - & - \\
\hline Pereira & $\mathbf{X}$ & $\mathbf{X}$ & $\mathbf{X}$ & $\checkmark$ & $\mathbf{X}$ & - & $\checkmark$ & - & - & $\mathbf{X}$ & $\mathbf{X}$ & $\mathbf{X}$ & - & $\checkmark$ & $\checkmark$ & $\checkmark$ & - & - & $\mathbf{X}$ & $\mathbf{X}$ & $\mathbf{X}$ & & & & $\checkmark$ & - & - \\
\hline
\end{tabular}

This table shows the results of the homogeneity test for permanent workers, where $w, y$ and $t f p$ stand for real wage, output and total factor productivity (TFP). The lower part of the matrix (below the diagonal), the label " $\checkmark$ " indicates that the null hypothesis that the long-run wage (output or TFP) elasticities of skilled workers are equal between each pair of cities cannot be rejected at $5 \%$ level of significance. The label "X" means that the hypothesis can be rejected. The label "-" is used when the long-run coefficients are not significantly different from zero

Table 3 Geographic homogeneity test on conditional labour demand for temporary workers. Source Dane-AMS; authors' calculations

\begin{tabular}{|c|c|c|c|c|c|c|c|c|c|c|c|c|c|c|c|c|c|c|c|c|c|c|c|c|c|c|c|}
\hline \multirow{2}{*}{$\begin{array}{c}\text { Unskilled } \rightarrow \\
\text { Skilled } \downarrow\end{array}$} & \multicolumn{3}{|c|}{ Bogotá } & \multicolumn{3}{|c|}{ Barranquilla } & \multicolumn{3}{|c|}{ Bucaramanga } & \multicolumn{3}{|c|}{ Cali } & \multicolumn{3}{|c|}{ Cartagena } & \multicolumn{3}{|c|}{ Manizales } & \multicolumn{3}{|c|}{ Medellín } & \multicolumn{3}{|c|}{ Pereira } & \multicolumn{3}{|c|}{ Cúcuta } \\
\hline & $w$ & $y$ & $t f p$ & $w$ & $y$ & $t f p$ & $w$ & $y$ & $t f p$ & $w$ & $y$ & $t f p$ & $w$ & $\boldsymbol{Y}$ & $t f p$ & $w$ & $Y$ & $t f p$ & $w$ & $y$ & $t f p$ & $w$ & $y$ & $t f p$ & $w$ & $Y$ & $T f p$ \\
\hline Bogotá & & & & $\mathbf{X}$ & $\mathbf{x}$ & $\mathbf{X}$ & $\mathbf{X}$ & - & - & - & $\checkmark$ & $\checkmark$ & - & $\mathbf{X}$ & $\mathbf{X}$ & - & $\mathbf{X}$ & $\mathbf{X}$ & $\checkmark$ & $\checkmark$ & $\checkmark$ & $\checkmark$ & $\mathbf{X}$ & $\mathbf{X}$ & $\mathbf{X}$ & $\mathbf{X}$ & - \\
\hline Barranquilla & - & - & - & & & & $\checkmark$ & - & - & - & $\checkmark$ & $\checkmark$ & - & $\checkmark$ & $\checkmark$ & - & $\mathbf{X}$ & $\mathbf{X}$ & $\checkmark$ & $\mathbf{X}$ & $\checkmark$ & $\checkmark$ & $\mathbf{X}$ & $\mathbf{X}$ & $\mathbf{X}$ & $\checkmark$ & - \\
\hline Bucaramanga & - & - & - & - & - & - & & & . & - & - & - & - & - & - & - & - & - & $\checkmark$ & - & - & $\checkmark$ & - & - & $\mathbf{X}$ & - & - \\
\hline Cali & - & - & - & - & - & - & - & - & - & & 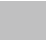 & . & - & $\mathbf{X}$ & $\mathbf{X}$ & - & $\mathbf{X}$ & $\mathbf{X}$ & - & $\checkmark$ & $\checkmark$ & - & $\mathbf{X}$ & $\mathbf{X}$ & - & $\checkmark$ & - \\
\hline Cartagena & - & - & - & - & - & - & - & - & - & - & - & - & & & & - & $\mathbf{X}$ & $\checkmark$ & - & $\mathbf{X}$ & $\mathbf{x}$ & - & $\checkmark$ & $\checkmark$ & - & $\checkmark$ & - \\
\hline Manizales & - & - & - & $\mathbf{X}$ & - & - & - & - & - & - & - & - & - & - & - & & & & - & $\mathbf{X}$ & $\mathbf{X}$ & - & $\mathbf{X}$ & $\mathbf{X}$ & - & $\mathbf{X}$ & - \\
\hline Medellín & - & $\checkmark$ & $\checkmark$ & - & - & - & - & - & - & - & - & - & - & - & - & - & - & - & & & & $\checkmark$ & $\mathbf{X}$ & $\mathbf{x}$ & $\mathbf{X}$ & $\mathbf{X}$ & - \\
\hline Pereira & - & - & - & - & - & - & - & - & - & - & - & - & - & - & - & - & - & - & - & - & - & & & & $\mathbf{X}$ & $\checkmark$ & - \\
\hline Cúcuta & - & - & - & - & - & - & - & - & - & - & - & - & - & - & - & - & - & - & - & - & - & - & - & - & & & \\
\hline
\end{tabular}

This table shows the results of the homogeneity test for permanent workers, where $w, y$ and tfp stand for real wage, output and total factor productivity (TFP). The lower part of the matrix (below the diagonal), the label " $\checkmark$ " indicates that the null hypothesis that the long-run wage (output or TFP) elasticities of skilled workers are equal between each pair of cities cannot be rejected at $5 \%$ level of significance. The label "X" means that the hypothesis can be rejected. The label "-" is used when the long-run coefficients are not significantly different from zero

these are: food products, textiles, apparel, chemicals, rubber and plastic, mineral products, metal products, and furniture. The demand for permanent skilled workers (Fig. 7a) displays larger responses to real wages than for temporary employees (Fig. 7b). At the same time demand for permanent unskilled workers (Fig. 7c) have higher elasticities than the demand for skilled ones (Fig. 7d). Food products, chemicals, and rubber and plastic show significant elasticities. The lowest value is found for temporary skilled workers in chemical plants
$(-0.284)$ and the highest for unskilled workers in textile plants $(-2.157)$.

Figure 8 shows that for the skilled permanent labour force (panel a), the highest value of output elasticity corresponds to chemicals (1.7) and the smallest to furniture (0.98). These estimates are greater for permanent skilled workers than for temporary ones in each industrial subsector. Mineral products for unskilled temporary workers (1.87) and metal products (0.82) represent the extreme values of output elasticities (Fig. 8d). In the case 


\section{a Permanent skilled}

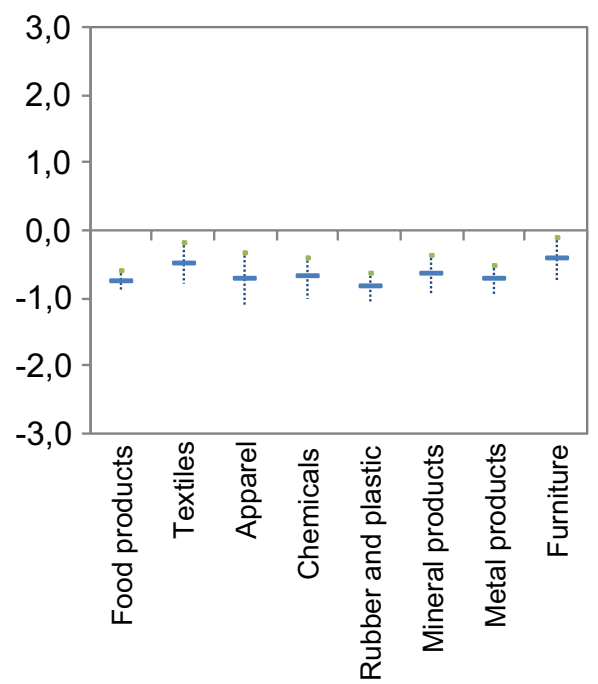

c Permanent unskilled

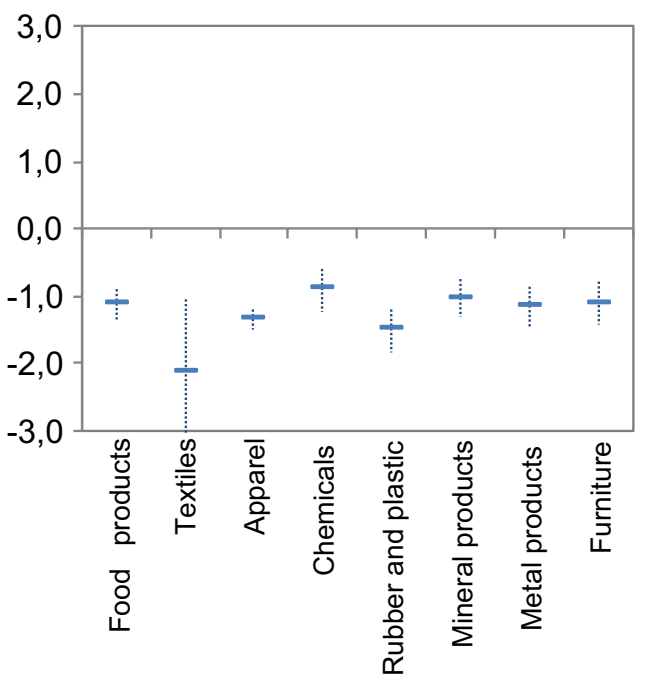

b Temporary skilled

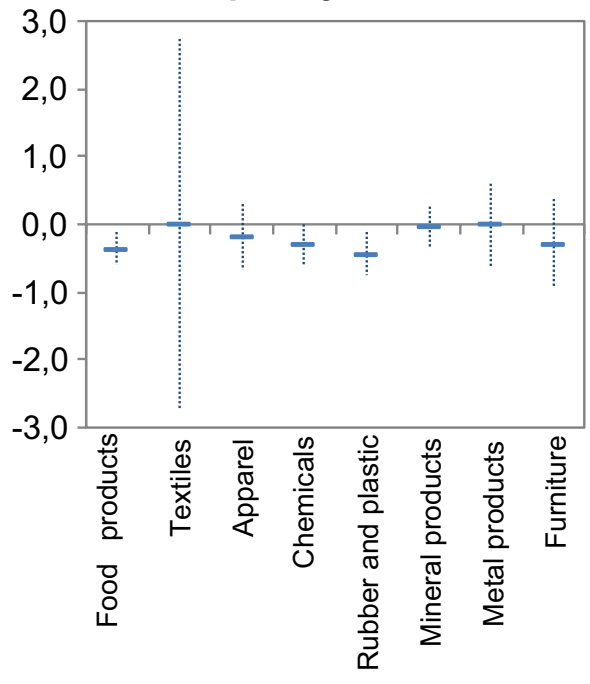

d Temporary unskilled



Fig. 7 Long-run own-price elasticity of conditional labour demand (2000-2013). 95\% confidence intervals (Source Dane-AMS and authors' calculations)

of unskilled permanent workers (Fig. 8c), besides rubber and plastic, whose coefficients are not statistically significant, output elasticities fluctuate between 0.85 and 1.42 . This result hints at myriad technologies and production functions across subsectors.

The TPF elasticity of labour demand is negative in general; when slightly positive it becomes not statistically significant. This is the case of metal (temporary skilled) and rubber and plastic (permanent unskilled). The TFP elasticity of permanent skilled workers fluctuates between -1.5 and -1.0 for almost all subsectors.

For skilled workers, the median adjustment length by subsector varies between 0.5 (temporary) and
2.26 years (permanent). The shortest halfway corresponds to the rubber and plastic subsector and the longest to chemicals. For unskilled workers, the halfway ranges between 0.97 (mineral products) and 6.2 (textiles) years. According to our results, adjustment costs for all skilled workers are higher than for unskilled (not shown).

Regardless of important numerical differences in longrun elasticities observed in Figs. 7 and 8, we cannot reject the null hypothesis of equality of coefficients in a vast majority of subsectors for the cases of permanent workers. That is, only with a few exceptions, in the case of ownprice elasticity (textiles and rubber and plastic, furniture 


\section{a Permanent skilled}

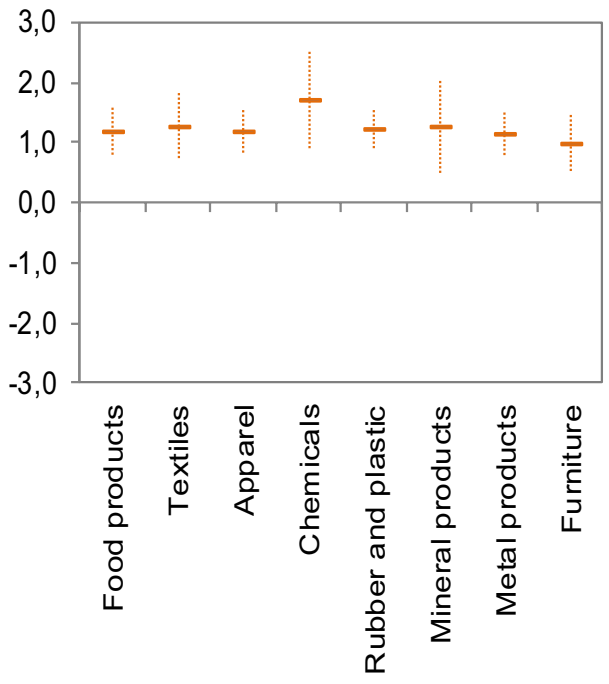

c Permanent unskilled

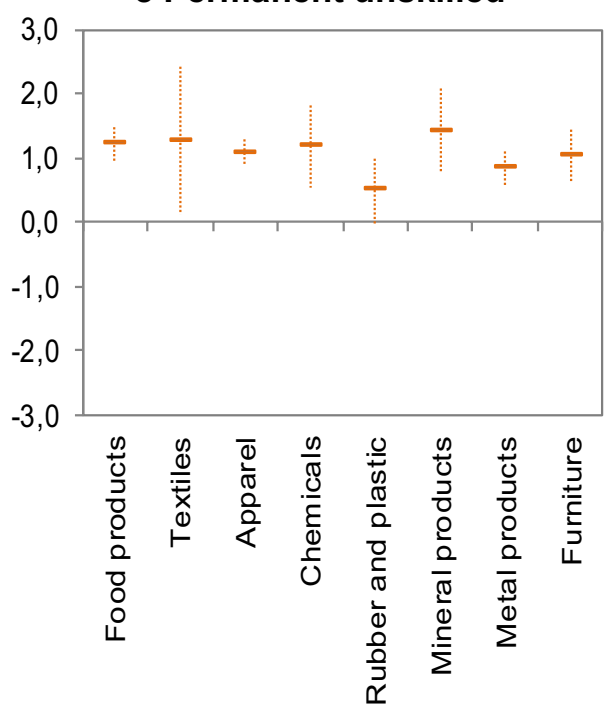

b Temporary skilled

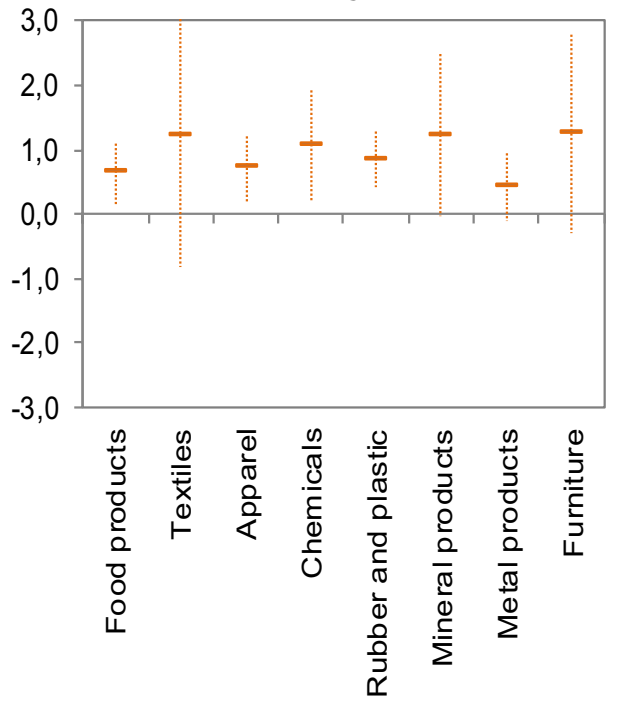

d Temporary unskilled

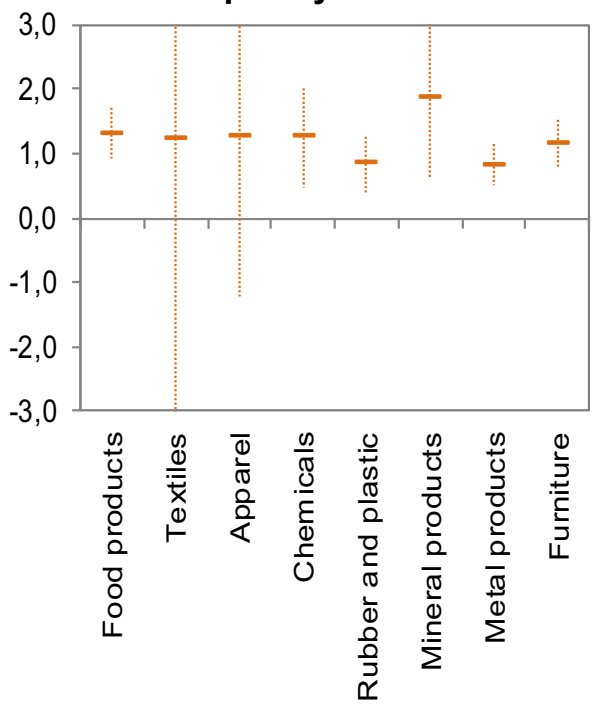

Fig. 8 Long-run output elasticity of conditional labour demand (2000-2013). 95\% confidence intervals (Source Dane-AMS and authors' calculations)

and rubber and plastics, and furniture with metal products), the results suggest that conditional demand for permanent skilled workers is homogeneous. Differences in output elasticity are found between chemicals and subsectors such as apparel, metal products, and furniture, while in the TFP elasticity the difference of chemical sector is with apparel. Thus, for this type of labour force, chemical shows significant differences in output and TFP elasticities. In the case of unskilled permanents workers, the results are diverse and heterogeneity seems to be a property. Differences are found mainly in the own-price elasticity of textile and mineral products subsectors (not shown).

For temporary workers the results are not conclusive given the high number of not significant long-run elasticities, which prevent us from computing the test in Eq. (2); thus, the set of comparisons declines notably. According to our results, only in a few cases we report no rejection of the null hypothesis. For skilled temporary workers, food products and rubber and plastic subsector elasticities are statistically equal while furniture, in the case of unskilled labour force, reports equalization of output elasticity with most subsectors except textiles and apparel.

All in all, after a visual comparison of Figs. 5, 6, 7 and 8 , we can conclude that labour demand in the manufacturing sector exhibits fewer disparities when it is estimated across subsectors than across cities for permanent workers. In fact, the long-run estimates of 
Table 4 Long-run labour demand elasticities (2000-2013). Source Dane-AMS; authors' calculations

\begin{tabular}{|c|c|c|c|c|}
\hline Specification & $\begin{array}{l}\text { Permanent } \\
\text { Skilled }\end{array}$ & Temporary & $\begin{array}{l}\text { Permanent } \\
\text { Unskilled }\end{array}$ & Temporary \\
\hline \multicolumn{5}{|l|}{ Medium size establishments } \\
\hline Own-price & $-0.514^{* * *}$ & $-0.382^{* * *}$ & $-1.008^{* * *}$ & $-0.351^{* * *}$ \\
\hline Auto-regressive coefficient & $0.228^{* *}$ & $0.252^{* * *}$ & $0.469^{* * *}$ & $0.370^{* * *}$ \\
\hline Halfway of adjustment & 0.469 & 0.503 & 0.915 & 0.697 \\
\hline Output & $1.081^{* * *}$ & $0.769^{* * *}$ & $0.486^{* * *}$ & $0.750^{* * *}$ \\
\hline TFP & $-0.983^{* * *}$ & $-0.601^{*}$ & $-0.353^{*}$ & $-0.906^{* * *}$ \\
\hline No. observations (plants) & 4937 & 1090 & 8320 & 4533 \\
\hline Hansen test ( $p$-value) & 0.595 & 0.480 & 0.249 & 0.356 \\
\hline Ar2 (p-value) & 0.233 & 0.652 & 0.000 & 0.986 \\
\hline \multicolumn{5}{|l|}{ Large size establishments } \\
\hline Own-price & $-0.722^{* * *}$ & $-0.170^{* * *}$ & $-1.150^{* * *}$ & $-0.231^{* * *}$ \\
\hline Auto-regressive coefficient & $0.394^{* * *}$ & $0.195^{* * *}$ & $0.547^{* * *}$ & $0.239^{* * *}$ \\
\hline Halfway of adjustment & 0.744 & 0.424 & 1.149 & 0.484 \\
\hline Output & $1.295^{* * *}$ & $1.087^{* * *}$ & $0.986^{* * *}$ & $0.356^{* * *}$ \\
\hline TFP & $-1.105^{* * *}$ & $-0.914^{* * *}$ & $-0.863^{* * *}$ & -0.212 \\
\hline No. observations (plants) & 8435 & 3433 & 9850 & 8365 \\
\hline Hansen test ( $p$-value) & 0.247 & 0.593 & 0.370 & 0.130 \\
\hline Ar2 (p-value) & 0.954 & 0.806 & 0.536 & 0.089 \\
\hline \multicolumn{5}{|l|}{ Very large size establishments } \\
\hline Own-price & $-1.106^{* * *}$ & $-0.591^{* * *}$ & $-1.018^{* * *}$ & -0.387 \\
\hline Auto-regressive coefficient & $0.671^{* * *}$ & $0.379^{* * *}$ & $0.692^{* * *}$ & $0.522^{* * *}$ \\
\hline Halfway of adjustment & 1.737 & 0.714 & 1.883 & 1.066 \\
\hline Output & $1.215^{* * *}$ & -0.055 & $1.503^{* *}$ & 0.333 \\
\hline TFP & $-1.113^{* *}$ & -0.029 & $-1.722^{* *}$ & 0.469 \\
\hline No. observations (plants) & 984 & 529 & 1023 & 1007 \\
\hline Hansen test ( $p$-value) & 1.000 & 1.000 & 1.000 & 1.000 \\
\hline Ar2 (p-value) & 0.794 & 0.426 & 0.158 & 0.590 \\
\hline
\end{tabular}

$*, * * * * *$ Correspond to $10 \%, 5 \%$ and $1 \%$ level of significance, respectively. Hansen test refers the accuracy of the set of instruments; the Ar 2 test shows that the errors do not exhibit autocorrelation of order two

labour demand are, no doubt, less volatile, more significant, and more homogenous in the former case than in the latter.

\subsection{Plant size heterogeneity}

Another potential source of labour demand heterogeneity is plant size. We categorize medium-sized plants as those that employ between 11 and 50 workers, large plants as those that employ between 51 and 500 workers, and very large plants more than 500 workers. According to Table 4, in all cases except temporary workers (both skilled and unskilled) in very large plants, the demand for labour is well defined in the sense that elasticities are significant and with the expected signs. The significant own-price long-run elasticities rank between -1.150 and -0.231 and are larger for permanent workers and larger plants, although the latter is also true for temporary workers. Here, as in Table 1, we also observe that the long-run real wage elasticity of open-ended contract workers is larger than it is for temporary workers regardless of their skills.

Demand for skilled labour is highly sensitive to output in large plants where the coefficient reaches 1.295 in the case of permanent workers. With respect to TFP elasticities, no clear patterns emerge in either the type of worker or the size of the plant. Median adjustment length is higher in very large plants and for permanent workers. The results of long-run elasticities homogeneity suggests that, for permanent workers, demand for skilled labour between medium, large, and very large establishments is not very different. The only exception is real wage elasticity between very large and medium-sized establishments. A high heterogeneity is found for unskilled permanent workers in the cases of output and technology. With respect to labour demand for temporary workers, only five significant differences, mostly in TFP elasticities, were found. 


\section{Conclusions}

Regional heterogeneity of labour market outcomes is a prevalent characteristic in Colombia. Using the AMS between 2000 and 2013, this paper estimates the determinants of skill-specific labour demand accounting for not only geographical heterogeneity but also across several other dimensions. The underlying motivation is the fact that formulating active labour market policies based on aggregate information about elasticities of labour demand might be seriously flawed.

The descriptive statistics shows three noticeable aspects. First, the behaviour of employment in the manufacturing sector seems to be driven by the pace of the four major cities: Bogotá, Barranquilla, Cali, and Medellín. The food and beverages, chemicals, apparel, rubber and plastic, and textiles subsectors contribute the most to employment generation by subsectors as well as large and very large plants by size. Second, the use of temporary contracts has increased markedly over time. This points to the search for lower labour costs and more flexible contract modalities; however, it creates a challenge as a larger number of temporary workers might affect firm productivity in the long run (see Castellani et al. 2017; Lisi and Malo 2017). Temporary contracts have been associated with fewer incentives to establish solid labour relations, training, etc. (Alaimo et al. 2015; Pierre and Scarpetta 2013; Addison and Teixeira 2003); this is a point that deserves further research. Third, the employment decline observed during the 2008-2009 economic crisis links industrial employment to aggregate demand, in particular for the goods produced by the establishments.

The article shows evidence that permanent (openended contract) workers, the sum of skilled and unskilled, display a higher long-run elasticity to real wage than temporary ones (see Table 1). This finding is in line with the substitution between temporary and permanent labour during the sample period. Skilled permanent and temporary workers have lower real wage elasticities than the respective unskilled employees. Under the conditional specification of labour demand, the temporary unskilled workers show an own-price elasticity of -0.438 and the skilled of -0.256 . This elasticity for unskilled workers with open-ended contracts is -1.109 while for skilled workers it is -0.682 . Thus, in-depth discussions about labour costs, wage rigidities, and wage-setting procedures are needed to avoid further segmentation in the labour market.

The estimation of long-run output elasticities confirms the well-established result that labour demand is more responsive to output than to its own price. Permanent workers show elasticities of 0.949 (skilled) and 1.198 (unskilled), larger than do temporary workers (0.710-skilled and 0.760-unskilled). The difference among these elasticities suggests that some flexible and versatile retraining programs should be part of the instruction of the labour force to be enacted when the economy is buffeted by shocks.

The demand for permanent skilled labour in Pereira is starkly different from that in Bogotá, Cali, and Medellín. The dominance of apparel in Pereira (see Fig. 2 above) might explain this finding. Labour demand in Bogotá is very similar to that in Medellín according to the three elasticities we analysed (own-price, output and TFP), while in the case of temporary workers, the demand for skilled labour in Cali is different from that in Bogotá and Medellín.

Shocks to the real wage have a greater effect on permanent workers, in particular in cities such as Manizales and Pereira. In the case of expansions or contractions of output, the demand for permanent skilled labour shows a significant response, mainly in cities such as Pereira. Demand for a temporary unskilled workforce shows high output elasticities in places like Manizales, Cartagena, and Pereira. While Manizales and Pereira have similar employment levels, in Pereira this is driven by apparel while in Manizales by food and beverages. The skilled own-price elasticity is larger in Manizales than Pereira, but output elasticity is larger in Pereira. As a result, we conclude that labour demand in the manufacturing sector is heterogeneous on regional grounds.

As stated above, this paper highlights the importance of considering disparities when the economy faces shocks different in nature. Indeed, we found that the determinants of industrial labour demand are quantitatively different, mainly, across regions. In fact, estimates of the long run estimates of labour demand are less volatile, more significant and homogenous, within subsectors. Nevertheless, subsectors with smaller output elasticity, such as rubber and plastic, might be safe havens during slumps, but less appealing than chemical products during expansions.

\section{Authors' contributions}

LEA, FC, and NO were involved in each stage of the article including data description, estimations, analysis and corrections. All authors read and approved the final manuscript.

\section{Author details \\ ${ }^{1}$ Banco de la República, Bogotá, Colombia. ${ }^{2}$ Inter-American Development Bank, Washington, USA. ${ }^{3}$ Ministry of Education, Bogotá, Colombia.}

\section{Acknowledgements}

We appreciate comments, corrections and suggestions by Giulia Lotti. We are grateful for the research assistance by María Paula Medina, Álvaro José Pinzón and Sergio Rivera. The usual disclaimers apply.

The opinions expressed here are not necessarily those of either the Banco de la República or its Board of Directors or the Inter-American Development or its Board of Executive Directors.

Some results mentioned here are not shown; they are omitted for space reasons. A more detailed and extensive version of this article can be found in http:// www.banrep.gov.co/sites/default/files/publicaciones/archivos/be_933.pdf. 


\section{Competing interests}

The authors declare that they have no competing interests.

\section{Availability of data and materials}

Data are not available. There is no permission to take the data away. Research must be conducted in the offices of the Official Colombian Bureau of Statistics (Departamento Administrativo Nacional de Estadística, or DANE). Users in the DANE's offices run the models and the results are sent to them a few days (weeks) later.

\section{Funding}

We did not have any funding.

\section{Publisher's Note}

Springer Nature remains neutral with regard to jurisdictional claims in published maps and institutional affiliations.

Received: 25 January 2018 Accepted: 24 December 2018

Published online: 09 January 2019

\section{References}

Addison, J.T., Teixeira, P.: The economics of employment protection. J. Labour Res. 24, 85-129 (2003)

Adam, A., Moutos, T.: Industry-level labour demand elasticities across the Eurozone: will there be any gain after the pain of internal devaluation? Bank of Greece Working Papers (2014)

Alaimo, V., Bosch, M., Kaplan, D.S., Pagés, C., Ripani, L.: Empleos para crecer, Inter American Development Bank (2015)

Arango, L.E., de la Mata, D., Obando, N.: Echoes of the crises in Spain and US in the Colombian labour market: a differences-in-differences approach. SERIEs 6, 441 (2015). https://doi.org/10.1007/s13209-015-0130-5

Arango, L.E.: Mercado de trabajo en Colombia: suma de partes heterogéneas. In: Arango L.E., Hamann F. (eds.) Mercado de trabajo en Colombia: hechos, tendencias e instituciones, pp. 167-195. Banco de la República. http://www.banrep.gov.co/es/libro-mercado-colombia (2013)

Arango, C.A., Rojas, A.M.: Demanda laboural en el Sector Manufacturero Colombiano: 1977-1999. Ensayos Sobre Política Económica. 44, 96-154 (2004)

Arellano, M., Bover, O.: Another look at the instrumental variable estimation of error-components models. J. Econ. 68, 29-51 (1995)

Bande, R., Fernández, M., Montuenga, V.: Regional unemployment in Spain: disparities, business cycle and wage setting. Labour Econ. 15, 885-914 (2008)

Bartik, T.J.: How effects of local demand shocks vary with local labour market conditions. Upjohn Institute Working Paper. pp. 14-202 (2014)

Beaudry, P., Green, D.A., Sand, B.M.: In search of labour demand. NBER Working Papers. WP 20568 (2014)

Bernal, R., Cardenas, M.: Determinants of labour demand in Colombia: 1976-1996. NBER Working Papers. WP 10077 (2003)

Blanchard, O.J., Katz, L.F.: Regional evolutions. Brookings Papers Econ. Act. 1, 1-75 (1992)

Blundell, R., Bond, S.: Initial conditions and moment restrictions in dynamic panel data models. J. Econometr. 87, 115-143 (1998)

Brame, R., Paternoster, R., Mazerolle, P., Piquero, A.: Testing for the equality of maximum-likelihood regression coefficients between two independent equations. J. Quant. Criminol. 14(3), 245-261 (1998)

Bresson, G., Kramarz, F., Sevestre, P.: Heterogenoues labor and the dynamics of aggregate labor demanda: some estimations using panel data. Empirical Economics 17, 153-168 (1992)

Cahuc, P., Carcillo, S., Zylberberg, A.: Labour economics. MIT Press, Cambridge (2004)

Cárdenas, C., Hernández, A., Torres, J.E.: A statistical analysis of heterogeneity on labour markets and unemployment rates in Colombia. Desarrollo y Sociedad. 75, 153-196 (2015)

Caponi, V:: Public employment policies and regional unemployment differences. Region. Sci. Urban Econ. 63, 1-12 (2017)
Castellani, F., Lotti, G., Obando, N.: Fixed or open-ended? labor contracts and productivity in the Colombian manufacturing sector. IDB Working Paper Series N IDB-WP-832 (2017)

Dao, M., Furceri, D., Loungani, P.: Regional labour market adjustments in the United States and Europe. In IMF Working Paper. 14/26 (2014)

Dinero: La cifra: $4.6 \%$ es la tasa de sindicalización en Colombia. https://www. dinero.com/edicion-impresa/la-grafica/articulo/46-es-la-tasa-de-sindi calizacion-en-colombia/223012. Accessed 28 April (2016)

Dumais, G., Ellison, G., Glaeser, E.L.: Geographic concentration as a dynamic process. Rev. Econ. Stat. 84(2), 193-204 (2002)

Elhorst, J.P.: The mystery of regional unemployment differentials: theoretical and empirical explanations. J. Econ. Surv. 17(5), 709-748 (2003)

Eslava, M., Haltiwanger, J., Kugler, A., Kugler, M.: Factor adjustments after deregulations: panel evidence from Colombian plants. Rev. Econ. Studies. 51(4), 529-557 (2010)

Fedesarrollo: Informe mensual del Mercado laboural. El sindicalismo en Colombia (2017)

Granato, N., Haas, A., Hamann, S., Niebuhr, A.: The impact of skill-specific migration on regional unemployment disparities in Germany. J. Region. Sci. 55(4), 513-539 (2015)

Hamermesh, D.: Labour demand. Princeton Academic Press, New Jersey (1993)

Judzik, D.: Heterogenous labour demand: sectoral elasticity and trade effects in the U.S., Germany and Sewden. MPRA Paper 62768, University Library of Munich, Germany

Kanbur, R., Venables, A.: Spatial inequality and development. OUP Oxford (2005)

Kaufman, B.E., Hotchkiss, J.L.: The economics of labour markets, Thomson (2006)

Kmenta, J.: Elements of Econometrics. The MacMillan Company, New York (1971)

Levinsohn, J., Petrin, A.: Estimating production functions using inputs to control for unobservables. Rev. Econ. Stud. 70, 317-341 (2003)

Lichter, A., Peichl, A., Siegloch, S.: The own-wage elasticity of labour demand: a meta-regression analysis. In IZA Discussion Paper Series. p. 7958 (2014)

Lindgreen, B.W.: Statistical theory. In Chap and Hall (1993). 4th edition (1993)

Lisi, D., Malo, L.M.: The impact of temporary employment on productivity. The importance of sectors'skill intensity. J. Labour Market Res. 50, 91-112 (2017)

Medina, C., Posso, C., Tamayo, J., Monsalve, E.: Dinámica de la demanda laboural en la industria manufacturera colombiana 1993-2009: una estimación panel VAR. In Arango, L.E., Hamann F. (eds.) Mercado de trabajo en Colombia: hechos, tendencias e instituciones, pp 289-333. Banco de la República. http://www.banrep.gov.co/es/libro-mercado-colombia (2013)

Nickel, S.: An investigation of the determinants of manufacturing employment in the United Kingdom. Rev. Econ. Stud. 51(4), 29-557 (1984)

Pierre, G., Scarpetta, S.: Do firms make greater use of training and temporary employment when labour adjustment costs are high? IZA J. Labour Policy 2, 15 (2013)

Roberts, M., Skoufias, E.: The long-run demand for skilled and less skilled labour in the Colombian manufacturing plants. Rev. Econ. Stat. 79(2), 330-334 (1997)

Sargent, T.: Estimation of dynamic labour demand schedules under rational expectations. J. Polit. Econ. 86(6), 1009-1044 (1978)

Thirlwall, A.P.: Regional unemployment as a cyclical phenomenon. Scottish J. Polit. Econ. 13, 205-219 (1996)

Sawilowsky, S.S.: Fermat, Schubert, Einstein, and Behrens-Fisher: the probable difference between two means when $\sigma_{1}^{2} \neq \sigma_{2}^{2}$. J. Mod. Appl. Stat. Methods 1(2), 461-472 (2002)

Vivas, A., Farne, S., Urbano, D.: Estimaciones de funciones de demanda de trabajo dinámicas para la economía colombiana, 1980-1996. Archivos de Macroeconomía-Departamento Nacional de Planeación. 092 (1998)

Welch, B.L.: The generalization of student's problem when several population variances are involved. Biometrika 1(2), 28-35 (1947)

Wickens, M.: Macroeconomic theory: a dynamic general equilibrium approach. Princeton University Press, Princeton (2011)

Windmeijer, F.: A finite sample correction for the variance of linear efficient two-step GMM estimators. J. Econometr. 126, 25-51 (2005)

Young, A.T.: US elasticities of substitution and factor augmentation at the industry level. Macroecon. Dyn. 17, 861-897 (2013) 